\title{
Interaction of Bupropion with Muscle-Type Nicotinic Acetylcholine Receptors in Different Conformational States ${ }^{\dagger}$
}

\author{
Hugo R. Arias ${ }^{\star}$, Fernanda Gumilar $\ddagger$, Avraham Rosenberg", Katarzyna M. Targowska- \\ Duda $^{\perp}$, Dominik Feuerbach ${ }^{£}$, Krzysztof Jozwiak $^{\perp}$, Ruin Moaddel ${ }^{\|}$, Irving W. Wainer ${ }^{\|}$, and \\ Cecilia Bouzat ${ }^{\ddagger}$
}

"Department of Pharmaceutical Sciences, College of Pharmacy, Midwestern University, Glendale, Arizona, USA ¥Instituto de Investigaciones Bioquímicas de Bahía Blanca, Universidad Nacional del Sur, CONICET, Bahía Blanca, Argentina "Gerontology Research Center, National Institute of Aging, $\mathrm{NIH}$, Baltimore, USA ${ }^{\perp}$ Department of Chemistry, Medical University of Lublin, Lublin, Poland ENeuroscience Research, Novartis Institutes for Biomedical Research, Basel, Switzerland

\begin{abstract}
To characterize the binding sites and the mechanisms of inhibition of bupropion on muscle-type nicotinic acetylcholine receptors (AChRs), structural and functional approaches were used. The results established that bupropion: (a) inhibits epibatidine-induced $\mathrm{Ca}^{2+}$ influx in embryonic muscle AChRs, (b) inhibits adult muscle AChR macroscopic currents in the resting/activatable state with 100-fold higher potency compared to that in the open state, (c) increases desensitization rate of adult muscle AChRs from the open state and impairs channel opening from the resting state, (d) inhibits $\left[{ }^{3} \mathrm{H}\right] \mathrm{TCP}$ and $\left[{ }^{3} \mathrm{H}\right]$ imipramine binding to the desensitized/carbamylcholine-bound Torpedo AChR with higher affinity compared to the resting/ $\alpha$-bungarotoxin-bound AChR, (e) binds to the Torpedo AChR in either state mainly by an entropy-driven process, and (f) interacts with a binding domain located between the serine (position 6') and valine (position 13') rings, by a network of van der Waals, hydrogen bond, and polar interactions. Collectively our data indicate that bupropion first binds to the resting AChR, decreasing the probability of ion channel opening. The remnant fraction of open ion channels is subsequently decreased by accelerating the desensitization process.

Bupropion interacts with a luminal binding domain shared with PCP that is located between the serine and valine rings, and this interaction is mediated mainly by an entropy-driven process.
\end{abstract}

Bupropion is an antidepressant that is also being marketed as an aid to smoking cessation (1, 2). The proposed mechanism of action for bupropion is that this drug inhibits the catecholamine reuptake in presynaptic neurons, modulating the concentrations of dopamine and norepinephrine in the synaptic cleft. However, the affinity of bupropion for the neurotransmitter transporter is only moderate, and there is not clear-cut evidence explaining the dual antidepressant and anti-nicotinic modes of action elicited by bupropion.

In addition to the current clinical uses of bupropion, this drug behaves pharmacologically as a noncompetitive antagonist (NCA) ${ }^{1}$ on several nicotinic acetylcholine receptors (AChRs) (3,

\footnotetext{
$\dagger$ This research was supported by grants from the Science Foundation Arizona and Stardust Foundation and the Office of Research and Sponsored Programs, Midwestern University (to H.R.), by grants from ANPCyT, CONICET, UNS, Loreal-UNESCO, and Fundación F. Fiorini (to C.B), by the FOCUS research subsidy from the Foundation for Polish Science (to K.J.). This research was also supported in part by the Intramural Research Program of the NIH, National Institute on Aging.

*To whom correspondence should be addressed: Department of Pharmaceutical Sciences, College of Pharmacy, Midwestern University, 19555 N. $59^{\text {th }}$ Ave., Glendale, AZ 85308, USA. Telephone: (623) 572-3589. Fax: (623) 572-3550. E-mail: harias@ midwestern.edu .
} 
4) [reviewed in (5)]. AChRs are the paradigm of the Cys-loop ligand-gated ion channel superfamily. This genetically-linked superfamily includes types $\mathrm{A}$ and $\mathrm{C} \gamma$-aminobutyric acid, type 35 -hydroxytryptamine (serotonin), and glycine receptors [reviewed in (6-9)]. The malfunctioning of these receptors has been considered as the origin of several neurological disorders [reviewed in $(8,10)]$. For example, the evidence showing a higher rate of smokers in depressed patients than in the general population supports a possible role of AChRs in depression mechanisms [reviewed in (11)]. In this regard, it has been reported that hypercholinergic neurotransmission, which is associated with depressed mood states, may be mediated through excessive neuronal AChR activation and that the therapeutic actions of many antidepressants may be mediated in part through inhibition of one or more AChRs [reviewed in (12)].

Previous studies have shown that tricyclic antidepressants (TCAs) behave as NCAs of both muscle-type (13) and neuronal-type AChRs (14). Their noncompetitive inhibitory mechanisms on different members of the Cys-loop ligand-gated ion channel superfamily have been elucidated $(13,15)$ [reviewed in (5)]. And more recently, the TCA binding site in the desensitized Torpedo AChR has been characterized by $\left[{ }^{3} \mathrm{H}\right] 2$-azidoimipramine photolabeling and molecular dynamics (16). Nevertheless, the mechanisms of AChR inhibition elicited by bupropion are poorly understood. In this regard, we want to determine the interaction of bupropion with muscle-type AChRs in different conformational states. To this end, we will use binding and functional approaches including radioligand competition binding assays using well known NCAs such as [piperidyl-3, 4- $\left.{ }^{3} \mathrm{H}(N)\right]-N-(1-(2$ thienyl)cyclohexyl)-3,4-piperidine $\left(\left[{ }^{3} \mathrm{H}\right] \mathrm{TCP}\right)$ and $\left[{ }^{3} \mathrm{H}\right]$ imipramine, $\mathrm{Ca}^{2+}$ influx and macroscopic current recordings, thermodynamic and kinetic measurements using column-immobilized Torpedo AChRs, and molecular docking and dynamics studies. These studies will aid in further drug development.

\section{EXPERIMENTAL PROCEDURES}

\section{Materials}

[Piperidyl-3, 4- $\left.{ }^{3} \mathrm{H}(N)\right]-\left(N-\left(1-\left(2\right.\right.\right.$ thienyl)cyclohexyl)-3,4-piperidine) $\left(\left[{ }^{3} \mathrm{H}\right] \mathrm{TCP} ; 42-45 \mathrm{Ci} /\right.$ $\mathrm{mmol})$, and $\left[{ }^{3} \mathrm{H}\right]$ imipramine hydrochloride $(47.5 \mathrm{Ci} / \mathrm{mmol})$ were obtained from PerkinElmer Life Sciences Products, Inc. (Boston, MA, USA), and stored in ethanol at $-20^{\circ} \mathrm{C}$.

Carbamylcholine chloride $(\mathrm{CCh})$, suberyldicholine dichloride, acetylcholine chloride (ACh), tetracaine hydrochloride, $( \pm)$-epibatidine, $( \pm)$-bupropion hydrochloride, sodium cholate, cholesterol, phosphatidylserine, sphingomyelin, phosphatidic acid, pepstatin, leupeptin, aprotinin, calpain I, calpain II, benzamidine, paramethylsulfonylfluoride (PMSF), and polyethylenimine were purchased from Sigma Chemical Co. (St. Louis, MO, USA).

Phencyclidine hydrochloride (PCP) was obtained through the National Institute on Drug Abuse (NIDA) (NIH, Baltimore, USA). $\alpha$-Bungarotoxin ( $\alpha$-BTx) was obtained from Invitrogen Co. (Carlsbad, CA, USA). [1-(Dimethylamino) naphtalene-5-sulfonamido] ethyltrimethylammonium perchlorate (dansyltrimethylamine) was purchased from Pierce Chemical Co. (Rockford, IL, USA). Salts were of analytical grade.

\footnotetext{
${ }^{1}$ Abbreviations: NCA, noncompetitive antagonist; AChR, nicotinic acetylcholine receptor; PCP, phencyclidine; $\left[{ }^{3} \mathrm{H}\right] \mathrm{TCP},[\mathrm{piperidyl}-3$, $\left.{ }^{4-}{ }^{3} \mathrm{H}(N)\right]-(N-(1-(2$ thienyl)cyclohexyl)-3,4-piperidine; $\mathrm{CCh}$, carbamylcholine; ACh, acetylcholine; $\alpha$-BTx, $\alpha$-bungarotoxin; RT, room temperature; BS buffer, binding saline buffer (50 mM Tris-HCl, $120 \mathrm{mM} \mathrm{NaCl}, 5 \mathrm{mM} \mathrm{KCl}, 2 \mathrm{mM} \mathrm{CaCl}_{2}, 1 \mathrm{mM} \mathrm{MgCl} 2, \mathrm{pH} 7.4$ ); $\mathrm{NCA}$, noncompetitive antagonist; $\mathrm{K}_{\mathrm{i}}$, inhibition constant; $\mathrm{K}_{\mathrm{d}}$, dissociation constant; $\mathrm{K}_{\mathrm{a}}$, association constant; $\mathrm{k}_{\text {off }}$, dissociation rate constant; $\mathrm{k}_{\mathrm{on}}$, association rate constant; $\mathrm{IC}_{50}$, ligand concentration that produces $50 \%$ inhibition (of binding or of agonist activation); $\mathrm{n}_{\mathrm{H}}$, Hill coefficient; EC 50, agonist concentration that produces 50\% AChR activation; TCA, tricyclic antidepressants; DMEM, Dulbecco's Modified Eagle Medium; FBS, fetal bovine serum; FLIPR, fluorescent imaging plate reader.
} 


\section{Preparation of $\mathrm{AChR}$ native membranes}

AChR native membranes were prepared from frozen Torpedo californica electric organs obtained from Aquatic Research Consultants (San Pedro, CA, USA) by differential and sucrose density gradient centrifugation, as described previously (17). Total AChR membrane protein was determined by using the bicinchoninic acid protein assay (Pierce Chemical Co.). Specific activities of these membrane preparations were determined by the decrease in dansyltrimethylamine $(6.6 \mu \mathrm{M})$ fluorescence produced by the titration of suberyldicholine into receptor suspensions $(0.3 \mathrm{mg} / \mathrm{mL})$ in the presence of $100 \mu \mathrm{M} \mathrm{PCP}$ and ranged from 1.0 to 1.2 $\mathrm{nmol}$ of suberyldicholine binding sites $/ \mathrm{mg}$ total protein $(0.5-0.6 \mathrm{nmol} \mathrm{AChR} / \mathrm{mg}$ protein). The $\mathrm{AChR}$ membrane preparations were stored at $-80^{\circ} \mathrm{C}$ in $12 \%$ sucrose.

\section{Preparation of the cellular membrane affinity chromatography (CMAC) column and chromatographic system}

The CMAC-Torpedo AChR column was prepared by the immobilization of solubilized Torpedo membranes following a previously described protocol (18). Torpedo membranes were first homogenized in buffer A ( $50 \mathrm{mM}$ Tris- $\mathrm{HCl}$ buffer, $\mathrm{pH} 7.4$, containing $1 \mathrm{mM}$ pepstatin A, $0.02 \mathrm{mM}$ leupeptin, $1 \mathrm{mM}$ aprotinin, $1 \mathrm{mM}$ calpain I, $1 \mathrm{mM}$ calpain II, $1 \mathrm{mM}$ benzamidine, 2 $\mathrm{mM} \mathrm{MgCl}, 3 \mathrm{mM} \mathrm{CaCl}_{2}, 5 \mathrm{mM} \mathrm{KCl}$, and $0.2 \mathrm{mM} \mathrm{PMSF}$ ), and subsequently solubilized in buffer A containing $2 \%(\mathrm{w} / \mathrm{v})$ sodium cholate and $1 \mathrm{~mL}$ glycerol, in the presence of $100 \mathrm{nM}$ cholesterol, $60 \mu \mathrm{M}$ phosphatidylserine, $20 \mu \mathrm{M}$ sphingomyelin, and $60 \mu \mathrm{M}$ phosphatidic. Then, $200 \mathrm{mg}$ of the Immobilized Artificial Monolayer (IAM) liquid chromatographic stationary phase (ID = $12 \mu \mathrm{m}, 300 \AA$ A pore; Regis Chemical Co.) was suspended in the supernatant, and the mixture was rotated at room temperature (RT) for $1 \mathrm{~h}$. The suspension was dialyzed against $1 \mathrm{~L}$ of $50 \mathrm{mM}$ Tris-saline buffer, pH 7.4, containing $5 \mathrm{mM}$ EDTA, $100 \mathrm{mM} \mathrm{NaCl}, 0.1 \mathrm{mM}$ $\mathrm{CaCl}_{2}$ and $0.1 \mathrm{mM}$ PMSF, for 1 day. The suspension was then centrifuged at $700 \times \mathrm{g}$ at $4{ }^{\circ} \mathrm{C}$ and the pellet (Torpedo-IAM) was washed three times with $10 \mathrm{mM}$ ammonium acetate buffer, $\mathrm{pH}$ 7.4. The stationary phase was packed into a HR 5/2 column (GE Healthcare, Piscataway, $\mathrm{NJ}$ ) to yield a $150 \mathrm{~mm} \times 5 \mathrm{~mm}$ (ID) chromatographic bed, the CMAC-Torpedo AChR column. Finally, the CMAC-Torpedo AChR column was attached to the chromatographic system Series 1100 Liquid Chromatography/Mass Selective Detector (Agilent Technologies, Palo Alto, CA, USA) equipped with a vacuum de-gasser (G $1322 \mathrm{~A}$ ), a binary pump (1312 A), an autosampler (G1313 A) with a $20 \mu \mathrm{L}$ injection loop, a mass selective detector (G1946 B) supplied with atmospheric pressure ionization electrospray and an on-line nitrogen generation system (Whatman, Haverhill, MA, USA). The chromatographic system was interfaced to a $250 \mathrm{MHz}$ Kayak XA computer (Hewlett-Packard, Palo Alto, CA, USA) running ChemStation software (Rev B.10.00, Hewlett-Packard).

A $10 \mu \mathrm{L}$ sample of $10 \mu \mathrm{M}$ bupropion was injected onto the CMAC-Torpedo AChR column, and bupropion was monitored in the positive ion mode using single ion monitoring at $\mathrm{m} / \mathrm{z}=$ $240.5[\mathrm{MW}+\mathrm{H}]^{+}$ion with the capillary voltage at $3000 \mathrm{~V}$, the nebulizer pressure at $35 \mathrm{psi}$, and the drying gas flow at $11 \mathrm{~L} / \mathrm{min}$ at a temperature of $350^{\circ} \mathrm{C}$.

\section{Cells expressing different muscle-type AChRs}

Human embryonic kidney (HEK293) cells were transfected with mouse $\alpha 1, \beta 1, \delta$, and $\varepsilon$ cDNA subunits using calcium phosphate precipitation at a subunit ratio of $2: 1: 1: 1$ for $\alpha 1: \beta 1: \delta: \varepsilon$, respectively, essentially as previously described $(19,20)$. For transfections, cells at $40-50 \%$ confluence were incubated for $8-12 \mathrm{~h}$ at $37^{\circ} \mathrm{C}$ with the calcium phosphate precipitate containing the cDNAs in Dulbecco's Modified Eagle Medium (DMEM) plus 10\% (v/v) fetal bovine serum (FBS). A plasmid encoding green fluorescent protein (pGreen lantern was also included to allow identification of transfected cells under fluorescence optics. Cells were used for outside-out patch measurements 1 or 2 days after transfection. 
The TE671 cell line is a human rhabdomyosarcoma cell line (obtained from American Type Culture Collection, USA) that endogenously expresses the human fetal muscle AChR (i.e., $\alpha 1 \beta 1 \gamma \delta)$. TE671 cells were cultured in a 1:1 mixture of DMEM and Ham's F-12 Nutrient Mixture (Seromed, Biochrom, Berlin, Germany), supplemented with 10\% (v/v) FBS. DMEM/ Ham's F-12 contains $1.2 \mathrm{~g} / \mathrm{L} \mathrm{NaHCO}_{3}, 3.2 \mathrm{~g} / \mathrm{L}$ sucrose, and stable glutamine, as previously described (21). The cells were incubated at $37^{\circ} \mathrm{C}, 5 \% \mathrm{CO}_{2}$ and $95 \%$ relative humidity. For passaging, the cells were detached from the cell culture flask by washing with phosphatebuffered saline and brief incubation ( $3-5 \mathrm{~min})$ with trypsine $(0.5 \mathrm{mg} / \mathrm{mL}) /$ EDTA $(0.2 \mathrm{mg} / \mathrm{mL})$. The cells were passaged every 3 days.

\section{$\mathrm{Ca}^{2+}$ influx measurements in TE671 cells}

$\mathrm{Ca}^{2+}$ influx was determined as previously described (21). Briefly, $5 \times 10^{4} \mathrm{TE} 671$ cells per well were seeded $72 \mathrm{~h}$ prior to the experiment on black 96-well plates (Costar, New York, USA) and incubated at $37^{\circ} \mathrm{C}$ in a humidified atmosphere (5\% $\mathrm{CO}_{2} / 95 \%$ air). $16-24 \mathrm{~h}$ before the experiment, the medium was changed to $1 \%$ BSA in HEPES-buffered salt solution (HBSS) (130 mM NaCl, $5.4 \mathrm{mM} \mathrm{KCl}, 2 \mathrm{mM} \mathrm{CaCl}_{2}, 0.8 \mathrm{mM} \mathrm{MgSO}_{4}, 0.9 \mathrm{mM} \mathrm{NaH}_{2} \mathrm{PO}_{4}, 25 \mathrm{mM}$ glucose, $20 \mathrm{mM}$ HEPES, $\mathrm{pH}$ 7.4). On the day of the experiment, the medium was removed by flicking the plates and replaced with $100 \mu \mathrm{L}$ HBSS/1\%BSA containing $2 \mathrm{mM}$ Fluo-4 (Molecular Probes, Eugene, Oregon, USA) in the presence of $2.5 \mathrm{mM}$ probenecid (Sigma, Buchs, Switzerland). The cells were incubated at $37^{\circ} \mathrm{C}$ in a humidified atmosphere (5\% $\mathrm{CO}_{2} / 95 \%$ air) for $1 \mathrm{~h}$. Plates were flicked to remove excess of Fluo-4, washed twice with HBSS/ $1 \%$ bovine serum albumin (BSA), and finally refilled with $100 \mu \mathrm{L}$ of HBSS containing different concentrations of bupropion, and pre-incubated for $5 \mathrm{~min}$. Plates were then placed in the cell plate stage of the fluorescent imaging plate reader (FLIPR) (Molecular Devices, Sunnyvale, CA, USA). A baseline consisting of 5 measurements of $0.4 \mathrm{sec}$ each was recorded. Epibatidine $(1 \mu \mathrm{M})$ was then added from the agonist plate (placed in the agonist plate stage of the FLIPR) to the cell plate using the FLIPR 96-tip pipettor simultaneously to fluorescence recordings for a total length of $3 \mathrm{~min}$. The laser excitation and emission wavelengths are 488 and $510 \mathrm{~nm}$, at $1 \mathrm{~W}$, and a CCD camera opening of $0.4 \mathrm{sec}$. In parallel experiments, $1 \mu \mathrm{M}$ epibatidine with different concentrations of bupropion were co-injected by several seconds.

\section{Patch-clamp recordings in HEK293 cells expressing mouse adult muscle AChRs}

For outside-out recordings, the pipette solution contained $140 \mathrm{mM} \mathrm{KCl}, 5 \mathrm{mM}$ EGTA, $5 \mathrm{mM}$ $\mathrm{MgCl}_{2}$ and $10 \mathrm{mM}$ HEPES, $\mathrm{pH}$ 7.3. Extracellular solution (ECS) contained $150 \mathrm{mM} \mathrm{NaCl}, 5.6$ $\mathrm{mM} \mathrm{KCl}, 1.8 \mathrm{mM} \mathrm{CaCl}_{2}, 5 \mathrm{mM} \mathrm{MgCl}_{2}$ and $10 \mathrm{mM}$ HEPES, $\mathrm{pH}$ 7.3. The patch was excised in this configuration and moved into position at outflow of a perfusion system. The perfusion system allows for a rapid $(0.1-1 \mathrm{~ms})$ exchange of the solution bathing patch. A series of applications of $300 \mu \mathrm{M}$ ACh were applied to the patch, as described before $(13,22)$. The duration of agonist pulse was $200 \mathrm{~ms}$. We recorded the responses following different protocols: $+/-$ protocol: the patch was exposed 2 min to bath solution containing different concentrations of bupropion before the application of the agonist-containing solution; $-/+$ protocol: pulse of agonist solution containing bupropion without preincubation; +/+ protocol: the patch was exposed 2 min to bath solution containing different concentrations of bupropion before the application of the agonist solution containing bupropion. All currents were referred to those recorded in the same cell in the absence of bupropion (-/- protocol). In these experiments, control currents were also recorded after each protocol to assess recovery of the original peak current.

Macroscopic currents were filtered at $5 \mathrm{kHz}$, digitized at $20 \mathrm{kHz}$ and stored on the hard disk. Data analysis was performed using IgorPro software (WaveMetrics Inc., Lake Oswego, OR). The ensemble mean current was calculated for 5-10 individual current traces. Mean currents were fitted by a single exponential function: 


$$
I_{(t)}=I_{0} \exp \left(-t / \tau_{d}\right)+I_{\infty}
$$

where $I_{0}$ and $I_{\infty}$ are the peak and the steady state current values, respectively, and $\tau_{d}$ is the decay time constant that measures the current decay due to desensitization. Current records were aligned with each other at the point where the currents had risen to $50 \%$ of its maximum level. Peak currents correspond to the value obtained by extrapolation of the decay current to this point. The ratio between the peak current or the desensitization rate in the presence ( $\mathrm{I}_{\text {bupropion }}$ ) and absence of the drug ( $\mathrm{I}_{\text {cont }}$ ) was plotted as a function of bupropion concentration and the curve was fitted to the Hill equation:

$$
\mathrm{I}_{\text {bupropion }} / \mathrm{I}_{\text {cont }}=\mathrm{IC}_{50}{ }^{\mathrm{n}_{\mathrm{H}}} / \mathrm{IC}_{50}{ }^{\mathrm{n}_{\mathrm{H}}}+[\text { bupropion }]^{\mathrm{n}_{\mathrm{H}}} \text { ) }
$$

where $\mathrm{IC}_{50}$ is the concentration of bupropion that produces $50 \%$ inhibition of the peak currents.

\section{Bupropion-induced inhibition of $\left[{ }^{3} \mathrm{H}\right] \mathrm{TCP}$ and $\left[{ }^{3} \mathrm{H}\right]$ imipramine binding to Torpedo AChRs in different conformational states}

We studied the influence of bupropion on either $\left[{ }^{3} \mathrm{H}\right] \mathrm{TCP}$ or $\left[{ }^{3} \mathrm{H}\right]$ imipramine maximal binding to the Torpedo AChR in the resting/ $\alpha$-bungarotoxin ( $\alpha$-BTx)-bound and desensitized/CChbound states. In this regard, AChR native membranes $(0.3 \mu \mathrm{M})$ were suspended in binding saline (BS) buffer (50 mM Tris- $\mathrm{HCl}, 120 \mathrm{mM} \mathrm{NaCl}, 5 \mathrm{mM} \mathrm{KCl}, 2 \mathrm{mM} \mathrm{CaCl} 2,1 \mathrm{mM}$ $\mathrm{MgCl}_{2}, \mathrm{pH} 7.4$ ) with $7 \mathrm{nM}\left[{ }^{3} \mathrm{H}\right] \mathrm{TCP}$ or $13 \mathrm{nM}$ in the presence of $1 \mathrm{mM} \mathrm{CCh}$ (desensitized/ CCh-bound state), or with $7 \mathrm{nM}\left[{ }^{3} \mathrm{H}\right] \mathrm{TCP}$ or $44 \mathrm{nM}\left[{ }^{3} \mathrm{H}\right]$ imipramine in the presence of $2 \mu \mathrm{M}$ $\alpha$-BTx (resting/ $\alpha$-BTx-bound state), and preincubated for $30 \mathrm{~min}$ at RT. $\alpha$-Bungarotoxin is a competitive antagonist that maintains the AChR in the resting (closed) state (23). Nonspecific binding was determined in the presence of $50 \mu \mathrm{M}$ PCP (desensitized/CCh-bound state experiments) or $100 \mu \mathrm{M}$ PCP (or alternatively $200 \mu \mathrm{M}$ tetracaine) (resting/ $\alpha$-BTx-bound state experiments), as was used previously $(24,25)$. The total volume was divided into aliquots, and increasing concentrations of bupropion were added to each tube and incubated for $2 \mathrm{~h}$ at RT. AChR-bound radioligand was then separated from free ligand by a filtration assay using a 48sample harvester system with GF/B Whatman filters (Brandel Inc., Gaithersburg, MD, USA), previously soaked with $0.5 \%$ polyethylenimine for $30 \mathrm{~min}$. The membrane-containing filters were transferred to scintillation vials with $3 \mathrm{~mL}$ of Bio-Safe II (Research Product International Corp, Mount Prospect, IL, USA), and the radioactivity was determined using a Beckman LS6500 scintillation counter (Beckman Coulter, Inc., Fullerton, CA, USA).

The concentration-response data were curve-fitted by nonlinear least squares analysis using the Prism software. The corresponding $\mathrm{IC}_{50}$ values were calculated using the following equation:

$$
\theta=1 /\left[1+\left([\mathrm{L}] / \mathrm{IC}_{50}\right)^{\mathrm{n}_{\mathrm{H}}}\right]
$$

where $\theta$ is the fractional amount of the radioligand bound in the presence of inhibitor at a concentration [L] compared to the amount of the radioligand bound in the absence of inhibitor (total binding). $\mathrm{IC}_{50}$ is the inhibitor concentration at which $\theta=0.5$ (50\% bound), and $\mathrm{n}_{\mathrm{H}}$ is the Hill coefficient. The $\mathrm{n}_{\mathrm{H}}$ values were summarized in Table 2.

Taking into account that the AChR presents one binding site for TCP $(25,26)$ and imipramine $(13,16)$, the observed $\mathrm{IC}_{50}$ values from the competition experiments described above were transformed into inhibition constant $\left(K_{\mathrm{i}}\right)$ values using the Cheng-Prusoff relationship (27): 


$$
K_{\mathrm{i}}=\mathrm{IC}_{50} /\left\{1+\left([\mathrm{NCA}] / K_{\mathrm{d}}{ }^{\mathrm{NCA}}\right)\right\}
$$

where [NCA] is the initial concentration of $\left[{ }^{3} \mathrm{H}\right] \mathrm{TCP}$ or $\left[{ }^{3} \mathrm{H}\right]$ imipramine, and $K_{\mathrm{d}}{ }^{\mathrm{NCA}}$ is the dissociation constant for $\left[{ }^{3} \mathrm{H}\right] \mathrm{TCP}[0.83 \mu \mathrm{M}$ in the resting state (25) and $0.25 \mu \mathrm{M}$ in the desensitized state (26)], and for $\left[{ }^{3} \mathrm{H}\right]$ imipramine in the desensitized and resting states $[0.8$ and $3.8 \mu \mathrm{M}$, respectively; (16)]. In addition, the free energy change $(\Delta \mathrm{G})$ of bupropion interacting with the Torpedo AChR was determined as [reviewed in (7)]:

$$
\Delta \mathrm{G}=R T \ln K_{i}
$$

where $R$ is the gas constant $\left(8.314 \mathrm{~J} \mathrm{~mol}^{-1} \mathrm{~K}^{-1}\right)$, and $T$ is the temperature in Kelvin. The calculated $\mathrm{K}_{\mathrm{i}}$ and $\Delta \mathrm{G}$ values for bupropion were summarized in Table 2.

\section{Determination of the binding kinetics for bupropion using the CMAC-Torpedo AChR column}

In the non-linear chromatography approach, concentration-dependent asymmetric chromatographic traces are observed due to slow adsorption/desorption rates. The mathematical approach used in this study to resolve these non-linear conditions was the Impulse Input Solution (28). The chromatographic data were analyzed using PeakFit v4.11 for Windows Software (SPSS Inc., Chicago, IL) following a previously reported protocol (29). The details of this approach and its application to the determination of the binding kinetics of non-competitive inhibitors to neuronal AChRs were presented earlier (29,30). Briefly, the resultant peaks were fitted to the Impulse Input Solution model by adjusting four variables, namely $\mathrm{a}_{0}-\mathrm{a}_{3}$. The $\mathrm{a}_{2}$ variable was directly used for the calculation of the dissociation rate constant $\left(\mathrm{k}_{\mathrm{off}}\right)$ according to this equation:

$$
\mathrm{k}_{\mathrm{off}}=1 /\left(\mathrm{a}_{2} t_{0}\right)
$$

where the dead time of the column, $t_{0}$, is determined as the time required for the elution of water. The $a_{3}$ value was used to calculate the association constant $\left(K_{a}\right)$ for the formation of the ligand-receptor complex in equilibrium using this relationship:

$$
\left.\mathrm{K}_{\mathrm{a}}=\mathrm{a}_{3} / \text { [bupropion }\right]
$$

where [bupropion] is the concentration of bupropion. Both $\mathrm{K}_{\mathrm{a}}$ and $\mathrm{k}_{\text {off }}$ values can be used to further calculate the association rate constant, $\mathrm{k}_{\mathrm{on}}\left(\mathrm{k}_{\mathrm{on}}=\mathrm{K}_{\mathrm{a}} \cdot \mathrm{k}_{\mathrm{off}}\right)$.

\section{Thermodynamic parameters of Torpedo AChR-bupropion interactions}

Chromatographic elutions of bupropion from the CMAC-Torpedo AChR column were carried out at the following temperatures: $10,12,16,20$, and $25^{\circ} \mathrm{C}$. The elution procedure was conducted using a mobile phase composed of $10 \mathrm{mM}$ ammonium acetate buffer ( $\mathrm{pH}$ 7.4):methanol $(85: 15, \mathrm{v} / \mathrm{v})$ delivered at a flow rate of $0.2 \mathrm{~mL} / \mathrm{min}$. For the first set of experiments, the CMAC-Torpedo AChR column was equilibrated by passing $125 \mathrm{nM} \alpha$-BTx to the mobile phase through the column for $1 \mathrm{~h}$. In addition, a new column was treated with a $10 \mu \mathrm{L}$ injection of $1 \mathrm{mM}$ epibatidine, and the temperature studies were repeated. All studies were carried out in triplicate.

For the temperature-dependence studies, van't Hoff plots were constructed according to the following linear regression equation [reviewed in (7)]: 


$$
\ln \mathrm{K}_{\mathrm{a}}=\left(\Delta S^{\circ} / R\right)-\left(\Delta H^{\circ} / R\right)(1 / T)
$$

where $\Delta \mathrm{S}^{\circ}$ and $\Delta H^{\circ}$ are the standard entropy change and standard enthalpy change, respectively. Finally, the free energy change at $293 \mathrm{~K}\left(\Delta \mathrm{G}^{20}\right)$ was calculated using the GibbsHelmholtz equation [reviewed in (7)]:

$$
\Delta \mathrm{G}^{20}=\Delta H^{\circ}-T \Delta S^{\circ}
$$

\section{Docking and molecular dynamics of R- and S-bupropion in muscle-type AChR ion channels}

Amino acid sequences in the $\mathrm{M} 2$ transmembrane segments of the AChR ion channel are highly conserved between different species and subunits. However, the absolute numbering of amino acid residues varies greatly between subunits, thus, the residues in M2 of AChR subunits are referred to here using the prime nomenclature (1' to 20'), corresponding to residues Met $^{243}$ to $\mathrm{Glu}^{262}$ in the Torpedo AChR $\alpha$-subunit. As binding targets for modeling we used a structural model of the pore region of AChR based on the cryo-electron microscopy structure of the Torpedo AChR determined at $\sim 4$ Å resolution (PDB ID 2BG9) (32,33). A model of the mouse muscle AChR subtype was constructed using homology/comparative modeling method with Torpedo 2BG9 model used as a template.

Computational simulations were performed using the same protocol as recently reported (16). In the first step, R- and S-bupropion molecules were prepared using HyperChem 6.0 (HyperCube Inc., Gainesville, FL). Sketched molecules were optimized using the semiempirical method AM1 (Polak-Ribiere algorithm to a gradient lower than $0.1 \mathrm{kcal} / \mathrm{A} / \mathrm{mol}$ ) and then transferred for the subsequent step of ligand docking. The Molegro Virtual Docker (MVD 2008.2.4.0 Molegro ApS Aarhus, Denmark) was used for docking simulations of flexible ligands into the rigid target AChR model. In this step the complete structures of target receptors were used. The docking space was limited and centered on the middle of the ion channel and extended enough to ensure covering of the whole channel domain for sampling simulations (docking space was defined as a sphere of $21 \AA$ in diameter). The actual docking simulations were performed using the following settings: numbers of runs $=100$; maximal number of interactions $=10,000$; maximal number of poses $=10$ ), and the pose representing the lowest value of the scoring function (MolDockScore) for each ligand was selected for further simulations. In the last step, molecular dynamics were performed using the Yasara 6.10.18 package (Yasara Biosciences, Graz, Austria). Complexes of Torpedo or mouse muscle $\mathrm{AChR}$ ion channel models with bupropion isomers were edited to provide coordinates for the membrane domain only. For each subunit, M1-M4 transmembrane helices plus connecting loops were left in the system, all other parts of the protein were removed. These models were further inserted into periodic boxes ( $88 \AA \times 88 \AA \times 68 \AA$ ), and solvated with water molecules using the Yasara default algorithm. Although fixing constrains for backbone atoms were assigned, all side-chain atoms were left free to move during the simulations. In all further simulations the AMBER99 force field for both protein and ligand structures was used (Yasara BioSciences) with the cutoff $7.86 \AA$ and particle-mesh Ewald longrange function for electrostatic interactions. The initial complexes were pre-optimized with steepest descent method followed by 500 steps of simulated annealing. Finally, the actual $1.0 \mathrm{~ns}$ molecular dynamics was performed using the following parameters: temperature $=298 \mathrm{~K}$; multiple timesteps $=1 \mathrm{fs}$ for intramolecular and $2 \mathrm{fs}$ for intermolecular forces; PressureControl - waterprobe $(0.99 \mathrm{~g} / \mathrm{mL})$ ensemble. Snapshots of the simulations were saved every $5 \mathrm{ps}$.

The trajectories of molecular dynamics simulations were characterized by calculation of the emulated binding energy defined here as the difference between the energy of the complete 
complex system and a summation of energy of the ligand and the energy of the hydrated protein alone. All these calculations were performed with the same AMBER force field settings.

\section{RESULTS}

\section{Bupropion inhibits epibatidine-mediated $\mathrm{Ca}^{2+}$ influx in TE671 cells}

The change in fluorescence in TE671 cells after epibatidine stimulation is caused by an increase in intracellular $\mathrm{Ca}^{2+}$. The major source of $\mathrm{Ca}^{2+}$ is the extracellular buffer. Omission of $\mathrm{Ca}^{2+}$ from the extracellular solution does not produce the signal elicited by agonist stimulation (21). Epibatidine-induced $\alpha 1 \beta 1 \gamma \delta \mathrm{AChR}$ activation is blocked by pre-incubation $(\sim 5 \mathrm{~min})$ with bupropion with an inhibitory potency $\left(\mathrm{IC}_{50}\right)$ of $20.5 \pm 3.9 \mu \mathrm{M}$ (Table 1). Although the receptors are initially in the resting/activatable state (21) during pre-incubation with bupropion, the subsequent addition of the agonist will make them open and desensitize, and therefore the final effects of bupropion will be a combination of the effects at each state. In addition, the coinjection of epibatidine and bupropion produced an $\mathrm{IC}_{50}=10.5 \pm 2.1 \mu \mathrm{M}$ (Table 1). This value is identical to that obtained by ${ }^{86} \mathrm{Rb}^{+}$efflux experiments using the same human muscle AChR (4). Considering that this protocol is performed in the time regime of seconds, the observed blocking effect will be a combination of the effects elicited by bupropion on the open and desensitized ion channels. The fact that the $\mathrm{n}_{\mathrm{H}}$ values are close to unity (Table 1) indicates that both bupropion blocking processes are produced in a non-cooperative manner. In turn, this suggests that there is only one binding site for bupropion on each conformational state or that there are binding sites with similar affinity.

\section{Bupropion inhibits macroscopic AChR currents from resting and open states by different mechanisms}

To dissect the effects of bupropion on different conformational states, we studied its effects on outside-out patches rapidly perfused with $300 \mu \mathrm{M}$ ACh. To determine the state-dependence of bupropion action we used different perfusion protocols (see Experimental Procedures). In control data, the current reaches the peak after $0.1-1 \mathrm{~ms}$ and then decays with a time constant $\left(\tau_{\mathrm{d}}\right)$ of about $15-30 \mathrm{~ms}$ due to desensitization (Fig. 1). This $\tau_{\mathrm{d}}$ corresponds to a desensitization rate of $37 \pm 8 \mathrm{~s}^{-1}$, given that at saturating agonist concentrations $1 / \tau_{\mathrm{d}}$ is a good estimation of the desensitized rate. When bupropion is present only in the ACh activation solution $(-/+$ protocol), a concentration-dependent increase in the decay rate $\left(1 / \tau_{\mathrm{d}}\right)$ is observed (Fig. 1A). At $200 \mu \mathrm{M}$ bupropion, the decay rate increases to $294 \pm 10 \mathrm{~s}^{-1}$. A plot of the normalized decay rate as a function of bupropion concentrations yields an $\mathrm{IC}_{50}$ value of $40.1 \pm 5.1 \mu \mathrm{M}$ and a $\mathrm{n}_{\mathrm{H}}$ of $0.99 \pm 0.11$ (Table 1). No significant changes on the peak currents are observed under this protocol application. At all bupropion concentrations, decays are well fitted by a single exponential function. This observation discards a fast open-channel block mechanism, since a two-component decay time course should have been observed instead $(34,35)$. However, the observed monoexponential decay might also result from channel block with a slow unblocking rate, as described before for TCAs acting on muscle AChRs (13). Distinguishing between slow channel block and increased desensitization is not possible from these experiments.

To determine if bupropion affects AChR activation when acting through the resting/activatable state, we exposed the patch to bupropion for $2 \mathrm{~min}$, and then activated the receptors with an ACh solution free of the drug (+/- protocol). Pre-application of the drug decreases the peak current in a dose-dependent manner. No significantly changes in the decay rate were observed in the presence of different concentrations of bupropion with respect to control currents. After washing out the drug with bath solution the peak current can be completely recovered (95 \pm 2 $\%)$. Thus, the effects of bupropion are very different when it acts on the open state, where it increases the decay rate, or on the resting/activatable state, where it decreases the peak current. The $\mathrm{IC}_{50}$ calculated for the inhibition of the peak current is $0.40 \pm 0.04 \mu \mathrm{M}$ and the $\mathrm{n}_{\mathrm{H}}$ is 1.90 
\pm 0.30 (Table 1). Thus, the inhibitory potency is much higher when the drug acts from the resting/activatable state than from the open state. The decrease in the peak current produced by bupropion acting at the resting/activatable state may arise from block of resting channels or from an increase of the desensitization of resting channels.

To determine if the effects of bupropion on both states are additive, the patch was continuously exposed to the drug (+/+ protocol). For this experiment we used the drug concentrations corresponding to the $\mathrm{IC}_{50}$ values for the actions at each state. Thus, the patch was pre-incubated with $0.4 \mu \mathrm{M}$ bupropion and then activated with a solution containing $300 \mu \mathrm{M}$ ACh plus $40 \mu \mathrm{M}$ bupropion. The decrease of the peak current measured in the $+/+$ protocol is quantitatively similar to that measured using the $+/-$ protocol $(48.4 \pm 3.4 \%)$. Analogously, the decrease of the decay rate determined under the $+/+$ protocol is similar to that achieved under the $-/+$ protocol $(49.5 \pm 2.8 \%)$. In conclusion, the continuous exposure of the receptor to the drug produces the same inhibition as the sum of the individual effects at the resting/activatable and open states. Full recovery of the peak current and of the decay time constant $(93 \pm 6 \%)$ are achieved after washing the drug, indicating that the inhibition is reversible (Fig. 1C).

In conclusion, macroscopic current recordings show that bupropion inhibits AChR by two mechanisms mediated by binding to specific conformational states. More specifically, when bupropion binds to the resting/activatable state, channel opening is impaired, whereas when it binds to the open state, desensitization rate from the open state is increased or alternatively, slow channel block occurs.

\section{Bupropion-induced inhibition of $\left[{ }^{3} \mathrm{H}\right] \mathrm{TCP}$ or $\left[{ }^{3} \mathrm{H}\right]$ imipramine binding to $\mathrm{AChRs}$ in different conformational states}

We have previously characterized the binding sites for PCP/TCP $(24,25,36)$ and imipramine $(13,16)$ in Torpedo AChRs. Thus, we want to determine the location of the bupropion binding site relative to these NCA loci. To this end, we determined the influence of bupropion on either $\left[{ }^{3} \mathrm{H}\right] \mathrm{TCP}$ (Fig. 2) or [ $\left.{ }^{3} \mathrm{H}\right] \mathrm{imipramine}$ (Fig. 3) maximal binding to Torpedo AChRs in different conformational states. Bupropion inhibits $\sim 100 \%$ the specific binding of $\left[{ }^{3} \mathrm{H}\right] \mathrm{TCP}$ (Fig. 2) and $\left[{ }^{3} \mathrm{H}\right]$ imipramine (Fig. 3) to either the desensitized/CCh-bound or resting/ $\alpha$-BTx-bound state. The obtained $\mathrm{K}_{\mathrm{i}} \mathrm{s}$ (Table 2) indicate that bupropion binds to the Torpedo AChR in either the resting/ $\alpha$-BTx-bound or desensitized/CCh-bound state with practically the same affinity as TCAs $(13,16)$. Comparing the $\mathrm{K}_{\mathrm{i}}$ values in different conformational states, we can indicate that bupropion binds to the PCP and TCA binding sites with $\sim 2$-fold higher affinity in the desensitized/CCh-bound compared to that in the resting/a-BTx-bound state. The same binding affinity difference ( $\sim 1.5$-fold) was obtained by using frontal affinity chromatography (data not shown), confirming the radioligand binding results.

The fact that the calculated $\mathrm{n}_{\mathrm{H}}$ values are close to unity (Table 2) indicates that bupropion inhibits $\left[{ }^{3} \mathrm{H}\right] \mathrm{TCP}$ and $\left[{ }^{3} \mathrm{H}\right]$ imipramine binding in a non-cooperative manner. These data suggest that bupropion interacts with just one binding site, and that bupropion probably inhibits $\left[{ }^{3} \mathrm{H}\right]$ TCP and $\left[{ }^{3} \mathrm{H}\right]$ imipramine binding in a steric fashion. Schild-plot analyses of imiprimineinduced $\left[{ }^{3} \mathrm{H}\right] \mathrm{TCP}$ binding inhibition support this mechanism of competition (37).

\section{Binding kinetic parameters for bupropion determined by column-immobilized Torpedo AChRs}

Figure 4A shows the expected asymmetric traces for bupropion when it is chromatographed on the CMAC-Torpedo AChR column. The data were used to determine the $\mathrm{k}_{\text {off }}$ and $\mathrm{K}_{\mathrm{a}}$ values according to equations 6 and 7, respectively, and thus, to further calculate the $\mathrm{k}_{\text {on }}$ values for bupropion when it binds to the Torpedo AChR in different conformational states. These dynamic parameters might help to explain the observed $\sim 2$-fold higher affinity of bupropion 
for the desensitized AChR compared to the resting AChR (see Table 2). However, the results indicate that the dissociation rate constant $\left(\mathrm{k}_{\mathrm{off}}\right)$ of bupropion was practically the same when the column was exposed to either epibatidine (the AChR is mainly in the desensitized state) or $\alpha$-BTx (the AChR is mainly in the resting state) (see Table 3). This is also reflected by similar $\Delta \mathrm{G}$ values for the resting and desensitized states obtained by dynamic measurements (approximately $-31 \mathrm{~kJ} / \mathrm{mol}$ for both states; see Table 3), contrary to a small difference in the $\Delta \mathrm{G}$ values obtained by radioligand binding $(-33$ and $-30 \mathrm{~kJ} / \mathrm{mol}$ for the desensitized and resting states, respectively; see Table 2). In this regard, mechanisms other than ligand dynamics might explain the observed difference in the affinity of bupropion when the receptor is in different conformational states.

\section{Thermodynamic parameters for bupropion interacting with Torpedo AChRs}

In previous studies, an increase in the temperature produced a reduction in the chromatographic retention of dextromethorphan and levomethorphan (31). The data could then be analyzed using the van't Hoff plot to calculate the changes in enthalpy $\left(\Delta H^{\circ}\right)$ and entropy $\left(\Delta S^{\circ}\right)$ associated with the interactions of the ligands with the immobilized AChR. In this paper, nonlinear chromatography was used to calculate the $K_{a}$ constants to finally construct the van't Hoff plots. In this regard, temperature dependent changes in bupropion retention on immobilized Torpedo AChRs exposed to $\alpha$-BTx (resting state) were obtained. Since the resulting van't Hoff plot was linear (Fig. 5), the thermodynamic parameters $\Delta H^{\circ}$ and $\Delta S^{\circ}$ were calculated from the slopes and intercepts of the van't Hoff plots, respectively, according to eq. 8 , whereas $\Delta G^{20}$ was calculated according to eq. 9 (Table 4). Bupropion retention on immobilized Torpedo AChRs exposed to epibatidine (desensitized state) also produced the expected temperature dependence and thus, a linear van't Hoff plot (Fig. 5), allowing the calculation of the respective thermodynamic parameters (Table 4). The linearity of van't Hoff plots indicates an invariant retention mechanism over the temperature range studied $(31,38)$.

The entropic contributions (i.e., $-\mathrm{T} \Delta S^{\circ}$ values) for the $\mathrm{AChR}$-ligand interactions were calculated using the $\Delta S^{\circ}$ values from Table 4 at $293 \mathrm{~K}$. The results indicate that the entropic contributions are higher $(\sim-25$ and $-26 \mathrm{~kJ} / \mathrm{mol})$ than the enthalpic contributions $\left(\Delta H^{\circ} \sim-5\right.$ and $-6 \mathrm{~kJ} / \mathrm{mol}$; see Table 4 ), for the resting and desensitized states, respectively. This indicates that the bupropion-AChR interactions in both conformational states were mainly entropydriven [reviewed in (7)]. In this regard, bupropion may induce local or global conformational changes or solvent reorganization in the binding pocket [reviewed in (7)]. Negative $\Delta H^{\circ}$ values also suggest the existence of attractive forces (e.g., van der Waals, hydrogen bond, and electrostatic interactions) forming the stable complex. The calculated $\Delta G^{20}$ values (Table 4) coincide very well with that determined by either radioligand (see Table 2) or chromatographic (see Table 3) experiments. The thermodynamic parameters are similar in both the resting and desensitized states, suggesting that mechanisms other than thermodynamic differences might explain the observed $\sim 2$-fold higher affinity of bupropion for the desensitized state compared to the resting state.

\section{Molecular dynamics of bupropion interacting with Torpedo and mouse muscle AChR ion channels}

During molecular modeling simulations, R- and S-bupropion isomers were docked to models of Torpedo (Fig. 7A,B) and mouse muscle AChR ion channels (Fig. 7C), respectively. Molegro Virtual Docker generated a series of docking poses and ranked them using energy-based criterion using the embedded scoring function in MolDockScore. Based on this ranking, the lowest energy pose of the ligand-receptor complex was selected and presented in Fig. 7A,B (Torpedo model) and Fig. 7C (mouse muscle model), respectively. The MolDockScore values for best ranked complexes are presented in Table 5. These data only serve to compare the interaction of bupropion isomers with each AChR model (Torpedo and muscle mice AChRs, 
respectively), and are not expected to be considered reliable in absolute terms. In other words, these values cannot be compared to those obtained by other experimental procedures.

Molecular modeling results also indicate that either R- or S-bupropion in the neutral state, interacts within the middle portion of the channel in the cavity formed between valine (position 13') and serine (position 6') rings. Interestingly, the same docking site for both isomers in the protonated state was found (data not shown). A very similar mode of binding was observed in previous simulations where bupropion was docked into the $\alpha 3 \beta 4$ ion channel $(29,39)$. Analyses of the complexes show that the docked molecule interacts only with all five M2 helices, provided by each subunit. Comparison of Molegro scoring function values (see Table 5) suggest that both bupropion enantiomers present lower energies (a difference of approximately $-10 \mathrm{~kJ} / \mathrm{mol}$ ) of interaction with the mouse muscle AChR ion channel when compared to the Torpedo model.

Best scored complexes obtained by docking were edited and limited to membrane domain of the receptor and then subjected to molecular dynamics simulations as described in the Experimental Procedure section. To verify whether the ligand configuration is stable within the binding site, simulations were performed keeping the backbone of the protein frozen, while the ligand and all side-chains were left free to move. Although the simulations lasted for 1.0 $\mathrm{ns}$, the systems reached equilibrium after $0.2-0.25 \mathrm{~ns}$ as monitored by the trajectory of total energy (data not shown). During dynamics simulations, the molecules did not significantly change the position comparing to the starting pose, indicating that that simulated ligandreceptor complex is stable. In fact, the molecules interacted exclusively with nearby pore-lining residues at overlapping sites between the serine (position 6') and valine (position 13') rings, without interacting with the external or intracellular mouths of the ion channel. Table 5 includes the emulated binding energy values averaged during the $1.0 \mathrm{~ns}$ trajectory of molecular dynamics for each complex. Although these emulated measurements cannot be considered absolute values, they show that the calculated binding energy values fluctuate significantly during the dynamics simulations, producing standard deviations of $\sim 10 \%$ the averaged value. In this respect, there is no significant difference between the emulated binding energy values for bupropion in the neutral state interacting with either the Torpedo $\mathrm{AChR}$ or the mouse muscle $\mathrm{AChR}$. This lack of difference between both AChR types was also obtained using bupropion in the protonated state. Based on these results we did not pursue additional studies to demonstrate the difference between both isomers on muscle-type AChRs. However, further experiments need to be performed to demonstrate whether this is also true on neuronal-type AChRs such as the $\alpha 3 \beta 4 \mathrm{AChR}$ where bupropion also binds (4).

\section{DISCUSSION}

Bupropion clinically acts as an antidepressant and it is now also marketed as an aid to smoking cessation (2). Pharmacologically, bupropion also behaves as a NCA on several AChR types [reviewed in (5)]. In this regard, this study is an attempt to characterize the interactions of bupropion with different muscle-type AChRs in distinct conformational states and to determine its molecular mechanisms of inhibition. To this end, radioligand competition binding experiments, $\mathrm{Ca}^{2+}$ influx and macroscopic current recordings, thermodynamic and kinetic measurements, and molecular docking and dynamics studies were performed.

\section{Molecular mechanisms of inhibition mediated by bupropion}

In a first attempt to determine the effect of bupropion on epibatidine-activated $\mathrm{Ca}^{2+}$ influx in TE671 cells, pre-incubation and co-injection protocols were used. The inhibitory potency of bupropion was in the $10-20 \mu \mathrm{M}$ concentration range as was previously determined by ${ }^{86} \mathrm{Rb}^{+}$ efflux experiments using the same cell type (4). Since the $\mathrm{Ca}^{2+}$ influx approach could not distinguish the effect of bupropion on a particular conformational state, we recorded 
macroscopic currents of agonist-activated receptors rapidly pre-(mainly in the resting state) or co-incubated (mainly in the open state) with bupropion (Fig. 1).

Macroscopic currents show that the interaction of bupropion with the open state decreases the decay time constant of currents activated by $300 \mu \mathrm{M}$ ACh. At this ACh concentration, the decay rate equals the rate of desensitization from the double liganded open state (40). Thus, our results reveal that from the open state bupropion increases the desensitization rate. The current decay was adequately fitted using a single exponential function, which discards the possibility of a fast open-channel blockade mechanism. However, the occurrence of slow channel blockade, which has been described for other NCAs (41), maybe result in similar changes in macroscopic currents. If bupropion blocked the AChR and its unblocking process were quite slow, distinguishing between this process and the increase in the desensitization rate would be difficult (13).

Macroscopic current recordings also show a decrease in the peak current when bupropion interacts with the resting/activatable channel. Thus, together with the acceleration of decay rate from the open state, bupropion inhibits the opening of channels by binding to the resting/ activatable state. The latter effect might be due to either an increase in desensitization of the resting/activatable state or a direct blockade of unliganded channels. A similar effect is observed with TCAs (13). The potency of inhibition is greater when bupropion acts on the resting/activatable state than on the open state. A similar finding was reported for the inhibition of different Cys-loop receptors by TCAs $(15,42)$.

The two different effects detected for each different conformational state, i.e. reduced peak current and increased decay rate, are additive when the receptor is exposed continuously to the drug. Thus, the mechanism by which bupropion inhibits AChR function is selective for each conformational state.

\section{Characterization of the bupropion binding site}

The results from the radioligand competition binding (see Table 2) and frontal chromatographic (data not shown) experiments indicate that bupropion binds with higher affinity to the desensitized/agonist-bound Torpedo AChR compared to the resting/a-BTx-bound AChR.

Unfortunately, neither the dynamic nor the thermodynamic studies could explain the observed state-dependant ligand affinity (see Table 3).

The radioligand competition experiments also indicate that bupropion inhibits the binding of both $\left[{ }^{3} \mathrm{H}\right]$ imipramine and $\left[{ }^{3} \mathrm{H}\right] \mathrm{TCP}$ (the structural and functional analog of PCP) to both desensitized/CCh-bound and resting/ $\alpha$-BTx-bound AChRs with $n_{H}$ values close to unity (Table 2). Hill coefficients close to unity indicate a non-cooperative interaction between bupropion and PCP or imipramine, respectively, suggesting that bupropion interacts with only one binding site on each AChR conformational state. Although this evidence suggests a steric mode of competition between bupropion and PCP or imipramine, we cannot predict whether the location of the bupropion binding site is the same or distinct in each conformational state.

The location of the PCP binding site depends on the conformational state of the AChR ion channel [reviewed in (5)]. For instance, photoaffinity labeling studies using $\left[{ }^{3} \mathrm{H}\right]$ ethidium diazide, which binds with high affinity to the PCP locus, helped to determine the structural components of this site in the desensitized state (43). The results indicated that $\left[{ }^{3} \mathrm{H}\right]$ ethidium diazide mainly labeled residues at and close to the leucine ring (position 9') from the $\alpha 1-\mathrm{M} 2$ transmembrane segment. In addition, new photoaffinity labeling results using the hydrophobic probe 3-trifluoromethyl-3-(m-[ $\left.{ }^{125} \mathrm{I}\right]$ iodophenyl)diazirine suggest that the PCP binding site is located between the threonine (position 2') and serine (position 6') rings, closer to the cytoplasmic end of the desensitized ion channel (44). Our photoaffinity labeling studies using 
$\left[{ }^{3} \mathrm{H}\right] 2$-azidoimipramine supports the idea that TCAs bind to the PCP locus in the desensitized ion channel (16). On the other hand, site-directed mutagenesis studies determined that the PCP binding site in the open ion channel includes residues located between the serine (position 6') and leucine (position 9') rings (45). Finally, we suggested that the PCP binding site in the resting state is located closer to the external mouth than that in the desensitized and open states $(24,25,36)$. We also speculated that the aromatic tertiary amino group from the PCP (or TCP) molecule might interact with acidic residues (i.e., $\alpha 1-G^{2}{ }^{262}$ ) located at position 20 ' (e.g., the outer or extracellular ring) $(25,36)$ [reviewed in (5)]. Considering our previous findings, we suggest that the secondary amino group from the bupropion molecule can also be responsible for the binding to one of the two $\mathrm{Glu}^{262}$ residues by charge interactions, when the receptor is in the resting/ $\alpha$-BTx-bound state.

Proposed mechanisms of bupropion binding were additionally studied by molecular modeling. Docking simulations followed by molecular dynamics of R- and S-bupropion were performed on two different variants of the AChR membrane domain, Torpedo (Fig. 6A,B) and mouse muscle (Fig. 6C) AChRs. The results from the docking simulations indicate no enantioselective interactions: both enantiomers form ligand-receptor complexes characterized by similar values of scoring function (Table 5). Although there is no experimental evidence of bupropion enantioselectivity on AChRs, the (2R,3R)-hydroxy bupropion isomer inhibits the muscle-type $\mathrm{AChR}$ with 3.7-fold higher potency than the (2S,3S)-hydroxy bupropion isomer (46), indicating the possibility of bupropion enantioselectivity. In order to determine bupropion enantioselectivity in AChRs, bupropion isomers will be used in further functional and binding experiments.

The analysis of the obtained molecular complexes clearly indicates that bupropion in either the neutral (see Fig. 7) or protonated form (data not shown) binds to the middle portion of the channel between the serine (position 6') and valine rings (position 13'). Exactly the same locus was observed for PCP and imipramine in the Torpedo AChR ion channel (16). However, a distinction was observed in the $\alpha 3 \beta 4$ ion channel: bupropion in the protonated state interacted with the polar region of the intermediate ring (position 1'), whereas the neutral form was positioned between the valine/phenylalanine (position 15') and serine (position 8') rings (29). The pocket formed by the cleft between the phenyl ring provided by $\beta 4$-Phe and the isopropyl moiety from $\alpha 3-\mathrm{Val}$ interacts with the hydrophobic portion of bupropion, whereas hydrogen bonds are formed between polar residues at the serine ring and the polar region of bupropion. Considering this difference, distinct bupropion binding site locations may exist on each AChR ion channel. Nevertheless, we have to take into consideration that the $\alpha 3 \beta 4 \mathrm{AChR}$ ion channel was constructed by homology with the model of the 23 mer peptide imitating the M2 sequence of the Torpedo $\mathrm{AChR} \delta$ subunit (29), whereas the current model was based on the cryo-electron microscopy structure of the Torpedo AChR determined at $\sim 4$ A resolution (PDB ID 2BG9) $(32,33)$.

The evidence obtained by molecular docking on the Torpedo AChR supports the competition experiments (see Table 2), indicating that there is a binding site for antidepressants that overlaps the PCP binding site in the Torpedo AChR ion channel. The thermodynamic parameters indicate that bupropion interacts with the Torpedo AChR ion channel either in the resting or in the desensitize state mainly by an entropy-driven process (see Table 4), forming a network of van der Waals, hydrogen bond, and polar interactions.

Considering the above results, we envision a dynamic process where bupropion binds first to the resting AChR, probably close to the mouth of the ion channel, decreasing the probability of ion channel opening. The remnant fraction of open ion channels is subsequently decreased by accelerating the desensitization process, and less probable by an open-channel blocking mechanism. Bupropion inhibits AChR function by interacting with a binding domain shared 
by tricyclic antidepressants and by PCP that is located between the serine and valine rings. This drug-receptor interaction is mediated mainly by an entropy-driven process.

\section{Acknowledgements}

The authors thank to National Institute on Drug Addiction (NIDA, NIH, Bethesda, Maryland, USA) for its gift of phencyclidine. The authors also thank to Jorgelina L. Arias Castillo and Paulina Iacoban for their technical assistance, and to Dr. James Trudell (Stanford University, CA, USA) for his valuable comments on the thermodynamic studies.

\section{REFERENCES}

1. Hurt RD, Sachs DP, Glover ED, Offord KP, Johnston JA, Dale LC, Khayrallah MA, Schroeder DR, Glover PN, Sullivan CR, Croghan IT, Sullivan PM. A comparison of sustained-release bupropion and placebo for smoking cessation. N. Engl. J. Med 1997;337:1195-1202. [PubMed: 9337378]

2. Wonnacott S, Barik J. Nicotinic ACh Receptors. TOCRIS Rev 2007;28:1-20.

3. Slemmer JE, Martin BR, Damaj MI. Bupropion is a nicotinic antagonist. J. Pharmacol. Exp. Ther 2000;295:321-327. [PubMed: 10991997]

4. Fryer JD, Lukas RJ. Noncompetitive functional inhibition at diverse, human nicotinic acetylcholine receptor subtypes by bupropion, phencyclidine, and ibogaine. J. Pharmacol. Exp. Ther 1999;288:8892. [PubMed: 9862757]

5. Arias HR, Bhumireddy P, Bouzat C. Molecular mechanisms and binding site locations for noncompetitive antagonists of nicotinic acetylcholine receptors. Int. J. Biochem. Cell Biol 2006;38:1254-1276. [PubMed: 16520081]

6. Arias, HR. Ligand-gated ion channel receptor superfamilies. In: Arias, HR., editor. Biological and Biophysical Aspects of Ligand-Gated Ion Channel Receptor Superfamilies. India: Research Signpost; 2006. p. 1-25.

7. Arias, HR. Thermodynamics of nicotinic receptor interactions. In: Raffa, RB., editor. Drug-Receptor Thermodynamics: Introduction and Applications. USA: John Wiley \& Sons, Ltd; 2001. p. 293-358.

8. Hogg RC, Raggenbass M, Bertrand D. Nicotinic acetylcholine receptors: from structure to brain function. Physiol. Biochem. Pharmacol 2003;147:1-46.

9. Lester HA, Dibas MI, Dahan DS, Leite JF, Dougherty DA. Cys-loop receptors: new twists and turns. Trends Neurosci 2004;27:329-336. [PubMed: 15165737]

10. Lloyd GK, Williams M. Neuronal nicotinic acetylcholine receptors as novel drug targets. J. Pharmacol. Exp. Ther 2000;292:461-467. [PubMed: 10640281]

11. Picciotto MR, Brunzell DH, Caldarone BJ. Effect of nicotine and nicotinic receptors on anxiety and depression. Neuroreport 2002;13:1097-1106. [PubMed: 12151749]

12. Shytle RD, Silver AA, Lukas RJ, Newman MB, Sheehan DV, Sanberg PR. Nicotinic receptors as targets for antidepressants. Mol. Psychiatry 2002;7:525-535. [PubMed: 12140772]

13. Gumilar F, Arias HR, Spitzmaul G, Bouzat C. Molecular mechanisms of inhibition of nicotinic acetylcholine receptors by tricyclic antidepressants. Neuropharmacology 2003;45:964-976. [PubMed: 14573389]

14. Rana B, McMorn SO, Reeve HL, Wyatt CN, Vaughan PF, Peers C. Inhibition of neuronal nicotinic acetylcholine receptors by imipramine and desipramine. Eur. J. Pharmacol 1993;250:247-251. [PubMed: 7509283]

15. Gumilar F, Bouzat C. Tricyclic antidepressant inhibit homomeric Cys-Loop receptors by acting at different conformational states. Eur. J. Pharmacol 2008;584:30-39. [PubMed: 18314100]

16. Sanghvi M, Hamouda AK, Jozwiak K, Blanton MP, Trudell JR, Arias HR. Identifying the binding site(s) for antidepressants on the Torpedo nicotinic acetylcholine receptor: $\left[{ }^{3} \mathrm{H}\right] 2$-Azidoimipramine photolabeling and molecular dynamics studies. Biochem. Biophys. Acta 2008;1778:2690-2699. [PubMed: 18817747]

17. Pedersen SE, Dreyer EB, Cohen JB. Location of ligand-binding sites on the nicotinic acetylcholine receptor alpha-subunit. J. Biol. Chem 1986;261:13735-13743. [PubMed: 3093482] 
18. Moaddel R, Jozwiak K, Whittington K, Wainer IW. Conformational mobility of immobilized $\alpha 3 \beta 2$, $\alpha 3 \beta 4, \alpha 4 \beta 2, \alpha 4 \beta 4$ nicotinic acetylcholine receptors. Anal. Chem 2005;77:895-901. [PubMed: 15679359]

19. Bouzat C, Bren N, Sine SM. Structural basis of the different gating kinetics of fetal and adult nicotinic acetylcholine receptors. Neuron 1994;13:1395-1402. [PubMed: 7993630]

20. Bouzat C, Barrantes F, Sine SM. Nicotinic receptor fourth transmembrane domain: hydrogen bonding by conserved threonine contributes to channel gating kinetics. J. Gen. Physiol 2000;115:663-672. [PubMed: 10779322]

21. Michelmore S, Croskery K, Nozulak J, Hoyer D, Longato R, Weber A, Bouhelal R, Feuerbach D. Study of the calcium dynamics of the human $\alpha 4 \beta 2, \alpha 3 \beta 4$ and $\alpha 1 \beta 1 \gamma \delta$ nicotinic acetylcholine receptors. Naunyn-Schmiedebergs Arch. Pharmacol 2002;366:235-245. [PubMed: 12172706]

22. Liu Y, Dilger JP. Opening rate of acetylcholine receptor channels. Biophys. J 1991;60:424-432. [PubMed: 1717017]

23. Moore MA, McCarthy MP. Snake venom toxins, unlike smaller antagonists, appear to stabilize a resting state conformation of the nicotinic acetylcholine receptor. Biochim. Biophys. Acta 1995;1235:336-342. [PubMed: 7756343]

24. Arias HR, McCardy EA, Bayer EZ, Gallagher MJ, Blanton MP. Allosterically linked noncompetitive antagonist binding sites in the resting nicotinic acetylcholine receptor ion channel. Arch. Biochem. Biophys 2002;403:121-131. [PubMed: 12061809]

25. Arias HR, Trudell JR, Bayer EZ, Hester B, McCardy EA, Blanton MP. Noncompetitive antagonist binding sites in the Torpedo nicotinic acetylcholine receptor ion channel. Structure-activity relationship studies using adamantane derivatives. Biochemistry 2003;42:7358-7370. [PubMed: 12809491]

26. Pagán OR, Eterović VA, García M, Vergne D, Basilio CM, Rodríguez AD, Hann RM. Cembranoid and long-chain alkanol sites on the nicotinic acetylcholine receptor and their allosteric interaction. Biochemistry 2001;40:11121-11130. [PubMed: 11551210]

27. Cheng Y, Prusoff WH. Relationship between the inhibition constant $\left(\mathrm{K}_{\mathrm{i}}\right)$ and the concentration of inhibitor which causes 50 percent inhibition $\left(\mathrm{IC}_{50}\right)$ of an enzymatic reaction. Biochem. Pharmacol 1973;22:3099-3108. [PubMed: 4202581]

28. Wade JL, Bergold AF, Carr PW. Theoretical description of nonlinear chromatography, with applications to physicochemical measurements in affinity chromatography and implications for preparative-scale separations. Anal. Chem 1987;59:1286-1295.

29. Jozwiak K, Ravichandran S, Collins JS, Wainer IW. Interaction of noncompetitive inhibitors with an immobilized $\alpha 3 \beta 4$ nicotinic acetylcholine receptor investigated by affinity chromatography, quantitative-structure activity relationship analysis, and molecular docking. J. Med. Chem 2004;47:4008-4021. [PubMed: 15267239]

30. Moaddel R, Jozwiak K, Wainer IW. Allosteric modifiers of neuronal nicotinic receptors: New methods, new opportunities. Med. Res. Rev 2007;27:723-753. [PubMed: 17238157]

31. Jozwiak K, Hernandez S, Kellar KJ, Wainer IW. The enantioselective interactions of dextromethorphan and levomethorphan with the $\alpha 3 \beta 4$-nicotinic acetylcholine receptor: comparison of chromatographic and functional data. J. Chromatogr. B 2003;797:373-379.

32. Unwin N. Refined structure of the nicotinic acetylcholine receptor at $4 \AA$ resolution. J. Mol. Biol 2005;346:967-989. [PubMed: 15701510]

33. Miyazawa A, Fujiyoshi Y, Unwin N. Structure and gating mechanism of the acetylcholine receptor pore. Nature 2003;423:949-955. [PubMed: 12827192]

34. Dilger JP, Boguslavsky R, Barann M, Katz T, Vidal AM. Mechanisms of barbiturate inhibition of acetylcholine receptor channels. J. Gen. Physiol 1997;109:401-414. [PubMed: 9089445]

35. Forman SA. A hydrophobic photolabel inhibit nicotinic acetylcholine receptors via open-channel block following a slow step. Biochemistry 1999;38:14559-14564. [PubMed: 10545178]

36. Arias HR, Bhumireddy P, Spitzmaul G, Trudell JR, Bouzat C. Molecular mechanisms and binding site location for the noncompetitive antagonist crystal violet on nicotinic acetylcholine receptors. Biochemistry 2006;45:2014-2026. [PubMed: 16475790] 
37. Sullivan, CL.; Crundsen, M.; Arias, HR. USA: Phoenix, AZ; 2008. Characterization of antidepressant binding sites on the nicotinic acetylcholine receptor. 2008 ACCP Spring Practice and Research Forum. April 5-9.

38. Jozwiak K, Haginaka J, Moaddel R, Wainer IW. Displacement and nonlinear chromatographic techniques in the investigation of interaction of noncompetitive inhibitors with an immobilized $\alpha 3 \beta 4$ nicotinic acetylcholine receptor liquid chromatographic stationary phase. Anal. Chem 2002;74:4618-4624. [PubMed: 12349962]

39. Jozwiak K, Ravichandran S, Collins JR, Moaddel R, Wainer IW. Interaction of noncompetitive inhibitors with the $\alpha 3 \beta 2$ nicotinic acetylcholine receptor investigated by affinity chromatography and molecular docking. J. Med. Chem 2007;50:6279-6283. [PubMed: 17973360]

40. Spitzmaul G, Dilger JP, Bouzat C. The noncompetitive inhibitor quinacrine modifies the desensitization kinetics of muscle acetylcholine receptors. Mol. Pharmacol 2001;60:235-243. [PubMed: 11455009]

41. Papke RL, Oswald RE. Mechanisms of noncompetitive inhibition of acetylcholine-induced singlechannel currents. J. Gen. Physiol 1989;93:785-811. [PubMed: 2472461]

42. Choi J-S, Choi BH, Ahn HS, Kim M-J, Rhie D-J, Yoon SH, Min DS, Jo Y-H, Kim M-S, Sung K-W, Hahn SJ. Mechanism of block by fluoxetine of 5-hydroxytryptamine3 (5-HT 3 --mediated currents in NCB-20 neuroblastoma cells. Biochem. Pharmacol 2003;66:2125-2132. [PubMed: 14609737]

43. Pratt MB, Pedersen SE, Cohen JB. Identification of the sites of incorporation of $\left[{ }^{3} \mathrm{H}\right]$ ethidium diazide within the Torpedo nicotinic acetylcholine receptor ion channel. Biochemistry 2000;39:1145211462. [PubMed: 10985791]

44. Hamouda AK, Chiara DC, Blanton MP, Cohen JB. Probing the structure of the affinity-purified and lipid-reconstituted Torpedo nicotinic acetylcholine receptor. Biochemistry 2008;47:12787-12794. [PubMed: 18991407]

45. Eaton MJ, Labarca C, Eterović VA. M2 Mutations of the nicotinic acetylcholine receptor increase the potency of the non-competitive inhibitor phencyclidine. J. Neurosci. Res 2000;61:44-51. [PubMed: 10861798]

46. Damaj MI, Carroll FI, Eaton JB, Navarro HA, Blough BE, Mirza S, Lukas RJ, Martin BR. Enantioselective effects of hydroxyl metabolites of bupropion on behavior and on function of monoamine transporters and nicotinic receptors. Mol. Pharmacol 2004;66:675-682. [PubMed: 15322260] 

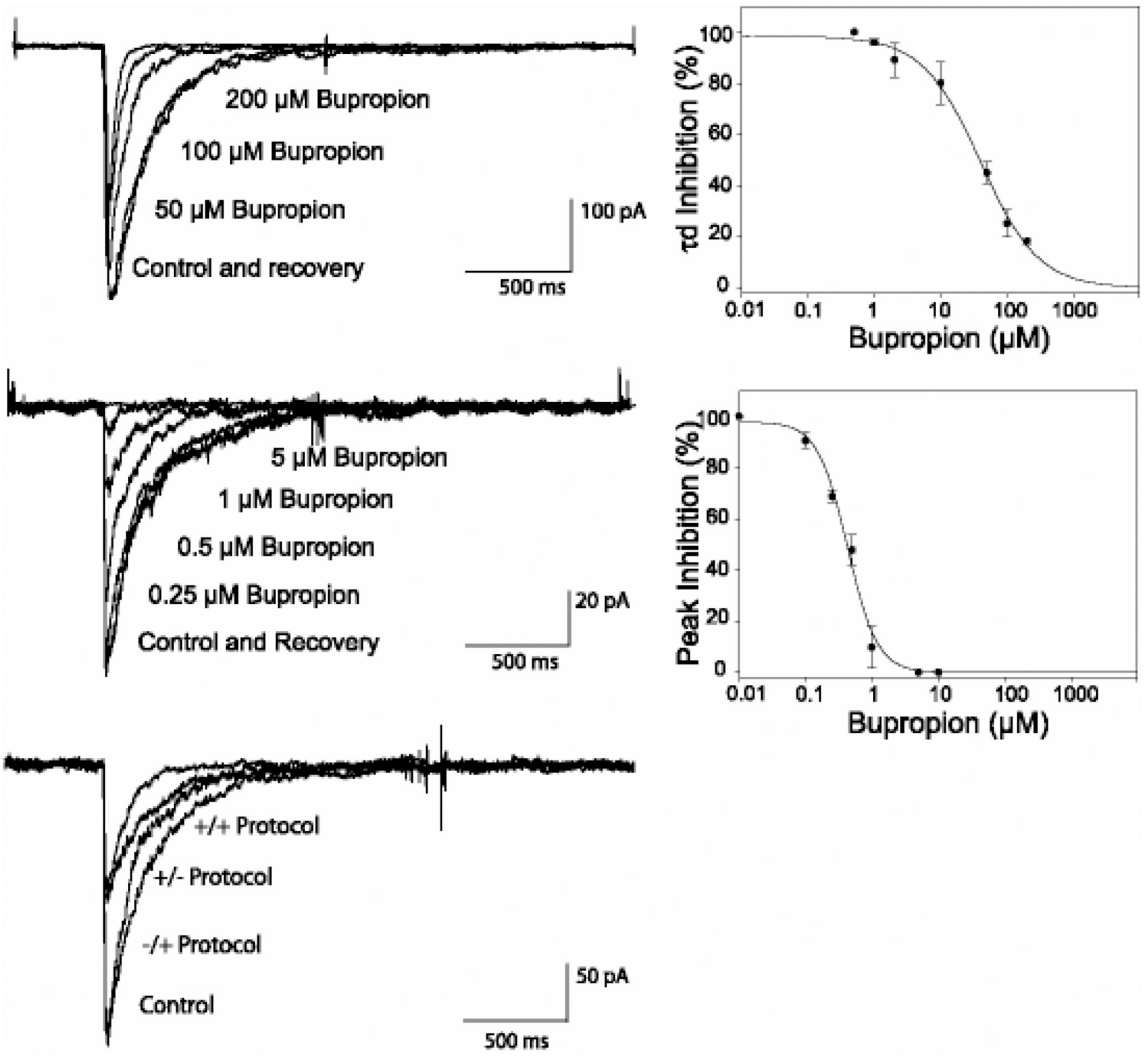

Fig. 1.

Effects of bupropion on agonist-induced macroscopic currents in HEK293 cells expressing mouse $\alpha 1 \beta 1 \varepsilon \delta$ (adult) AChRs.

A: Bupropion effects from the open state.

Left: Ensembled mean currents obtained from outside-out patches activated in absence (control) or simultaneous application of ACh and bupropion, without preincubation with bupropion (protocol -/+; open state). Each trace represents the average of 4-8 applications of agonist. Curves from right to left correspond to: control and recovery, 50, 100, and $200 \mu \mathrm{M}$ bupropion. The calculated decay time constants $\left(\tau_{\mathrm{d}}\right)$ are $25 \mathrm{~ms}$ for control and recovery curves, and 11.3, 6.3, and $4.5 \mathrm{~ms}$, for 50, 100, and $200 \mu \mathrm{M}$ bupropion, respectively. Membrane potential: $-50 \mathrm{mV}$.

Right: Concentration-response curve for the decrease in the decay time constant $(n=5)$. The calculated $\mathrm{IC}_{50}$ and $\mathrm{n}_{\mathrm{H}}$ values are summarized in Table 1 . 
B: Effects of bupropion from the resting/activatable state.

Left: Effect of bupropion application protocol +/- (resting/ activatable state): 2 min pre-

incubation of bupropion following ACh application. Each trace represents the average of 4-8 applications of agonist. Curves from right to left correspond to: control and recovery, 0.25 , $0.5,1$, and $5 \mu \mathrm{M}$ bupropion, respectively. The peak current decreases with increased bupropion concentrations. Membrane potential: $-50 \mathrm{mV}$.

Right: Concentration-response curve for the decrease in the peak current on the resting/ activatable state. The calculated $\mathrm{IC}_{50}$ and $\mathrm{n}_{\mathrm{H}}$ values are summarized in Table 1 .

C:Effects of bupropion application protocol on macroscopic currents.

Superimposed currents responses to $300 \mu \mathrm{M}$ ACh and bupropion concentrations correspond to $\mathrm{IC}_{50}$ for the resting/activatable state $(\sim 0.4 \mu \mathrm{M}$; see Table 1$)$ and for the open state $(\sim 40 \mu \mathrm{M}$ bupropion; see Table 1) using different protocols. From right to left curves correspond to control condition (-/-protocol; $\tau_{\mathrm{d}}=13.4 \mathrm{~ms}$ ), simultaneous $300 \mu \mathrm{M} \mathrm{ACh} / 40 \mu \mathrm{M}$ bupropion application without preincubation with bupropion $\left(-/+\right.$ protocol; $\tau_{\mathrm{d}}=6.5 \mathrm{~ms}$; peak current $99 \%$ of the control), ACh application following 2 min pre-incubation with $0.4 \mu \mathrm{M}$ bupropion (+/protocol; $\tau_{\mathrm{d}}=13.9 \mathrm{~ms}$; peak current $=50.4 \%$ of the control), and simultaneous $300 \mu \mathrm{M} \mathrm{ACh} /$ $40 \mu \mathrm{M}$ bupropion application after pre-incubation with $0.4 \mu \mathrm{M}$ bupropion $\left(+/+\right.$ protocol; $\tau_{\mathrm{d}}=$ $6.3 \mathrm{~ms}$; peak current $=47 \%$ of the control). 


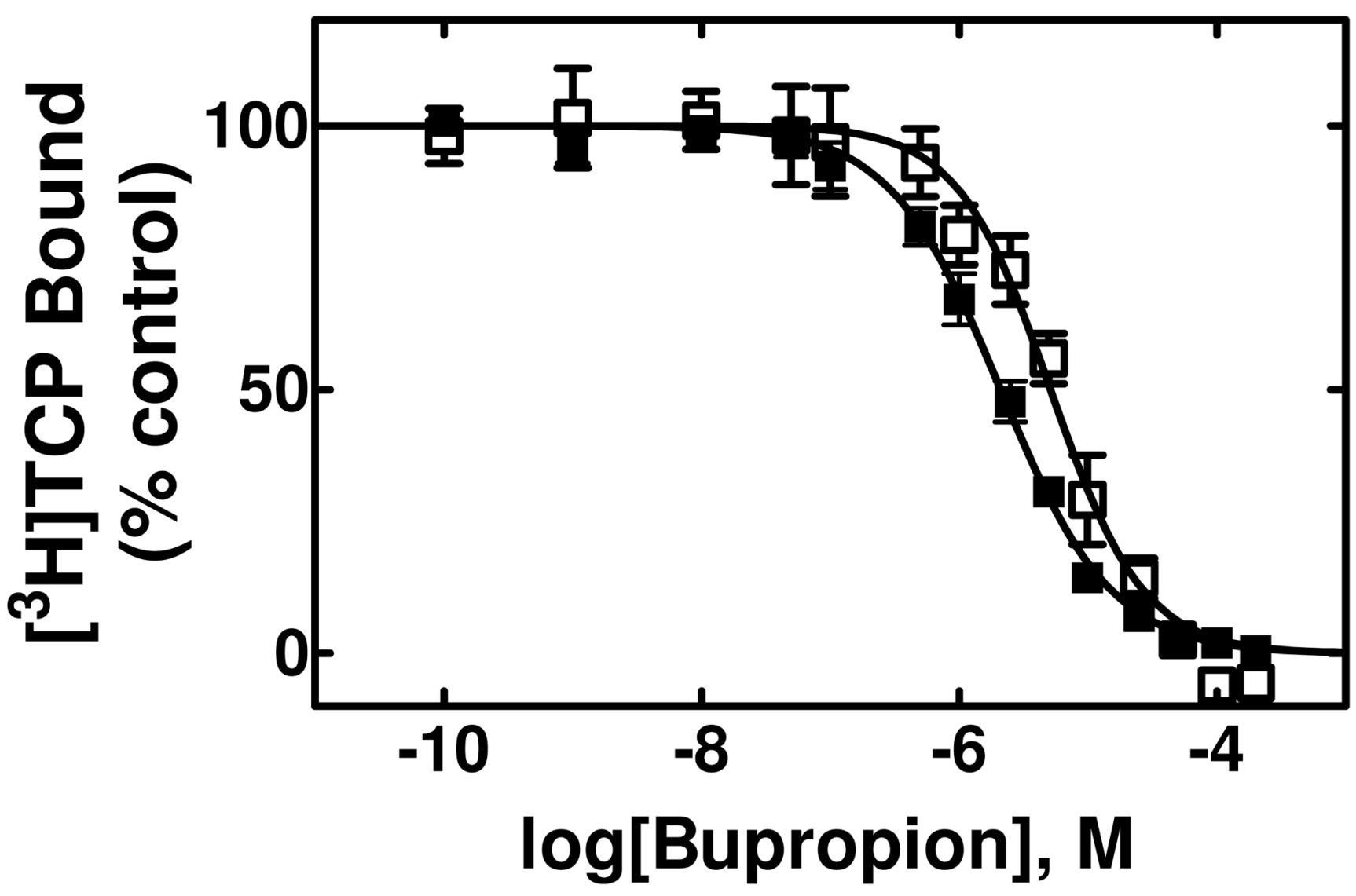

Fig. 2.

Bupropion-induced inhibition of $\left[{ }^{3} \mathrm{H}\right] \mathrm{TCP}$ binding to Torpedo AChRs in the desensitized (CCh-bound) ( $\boldsymbol{a})$ and resting ( $\alpha$-BTx-bound) ( $\square$ ) states. AChR-rich membranes $(0.3 \mu \mathrm{M})$ were equilibrated (2 h) with $7 \mathrm{nM}\left[{ }^{3} \mathrm{H}\right] \mathrm{TCP}, 1 \mathrm{mM} \mathrm{CCh}(\mathbf{\square})$ or $1 \mu \mathrm{M} \alpha$-BTx ( $\left.\square\right)$, and increasing concentrations of bupropion (i.e., $1 \mathrm{nM}-200 \mu \mathrm{M}$ ). Nonspecific binding was determined in the presence of 50 ( $\square)$ or $100 \mu \mathrm{M}$ PCP ( $\square)$, respectively. Each plot is the combination of two separated experiments each one performed in triplicate. From these plots the $\mathrm{IC}_{50}$ and $\mathrm{n}_{\mathrm{H}}$ values were obtained by nonlinear least-squares fit according to eq. 3. Subsequently, the $\mathrm{K}_{\mathrm{i}}$ values were calculated using eq. 4 . The calculated $\mathrm{K}_{\mathrm{i}}$ and $\mathrm{n}_{\mathrm{H}}$ values are summarized in Table 2. 


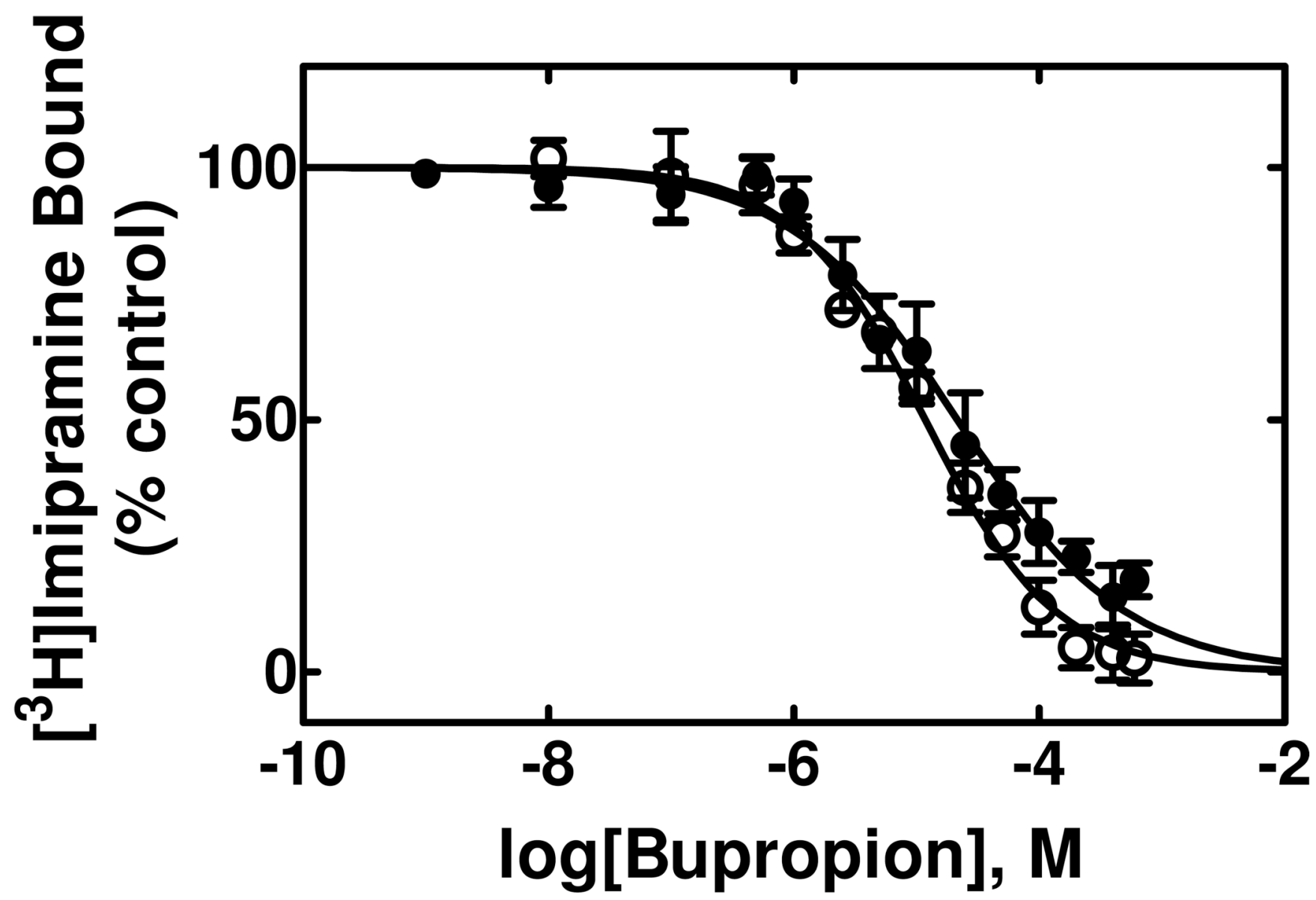

Fig. 3.

Bupropion-induced inhibition of $\left[{ }^{3} \mathrm{H}\right]$ imipramine binding to the AChR in the desensitized (CCh-bound) ( $($ ) and resting $(\alpha$-BTx-bound) $(\bullet)$ states. AChR-rich membranes $(0.3 \mu \mathrm{M})$ were equilibrated ( $2 \mathrm{~h}$ ) with $7 \mathrm{nM}\left[{ }^{3} \mathrm{H}\right]$ imipramine, $1 \mathrm{mMCCh}(\circ)$ or $1 \mu \mathrm{M} \alpha$-BTx $(\bullet)$, and increasing concentrations of bupropion (i.e., $1 \mathrm{nM}-200 \mu \mathrm{M}$ ). Nonspecific binding was determined in the presence of $100 \mu \mathrm{M}$ PCP (०) or $200 \mu \mathrm{M}$ tetracaine (•), respectively. Each plot is the combination of three separated experiments each one performed in triplicate. From these plots the $\mathrm{IC}_{50}$ and $\mathrm{n}_{\mathrm{H}}$ values were obtained by nonlinear least-squares fit according to eq. 3 .

Subsequently, the $K_{i}$ values were calculated using eq. 4 . The calculated $K_{i}$ and $n_{H}$ values are summarized in Table 2. 

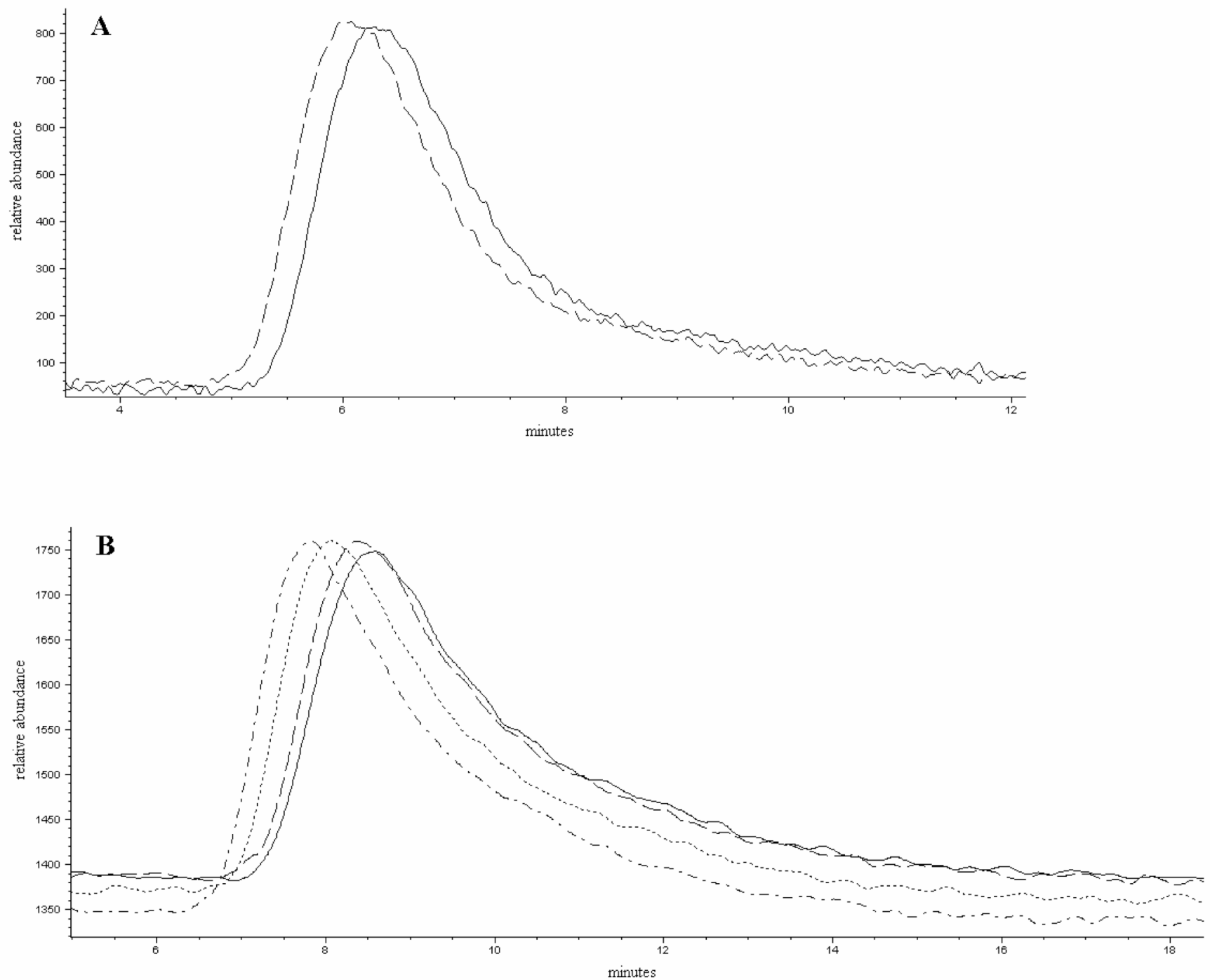

Fig. 4.

Chromatograhic elution of bupropion from the CMAC-Torpedo AChR column. (A) Bupropion is eluted from the column with ammonium acetate buffer $(10 \mathrm{mM}, \mathrm{pH} 7.4)$ and $15 \%$ methanol as the mobile phase, at $0.2 \mathrm{~mL} / \mathrm{min}$ and $20^{\circ} \mathrm{C}$. The dashed line represents the elution of bupropion from the CMAC-Torpedo AChR column pretreated with a-BTx (the immobilized AChR is mainly in the resting state), and the straight line represents the elution of bupropion from the CMAC-Torpedo $\mathrm{nAChR}$ column pretreated with epibatidine (the immobilized AChR is mainly in the desensitized state). (B) Bupropion is eluted from the CMAC-Torpedo AChR column pretreated with epibatidine (predominantly desensitized state) at different temperature (from right to left: $12,16,20$, and $25^{\circ} \mathrm{C}$ ). 


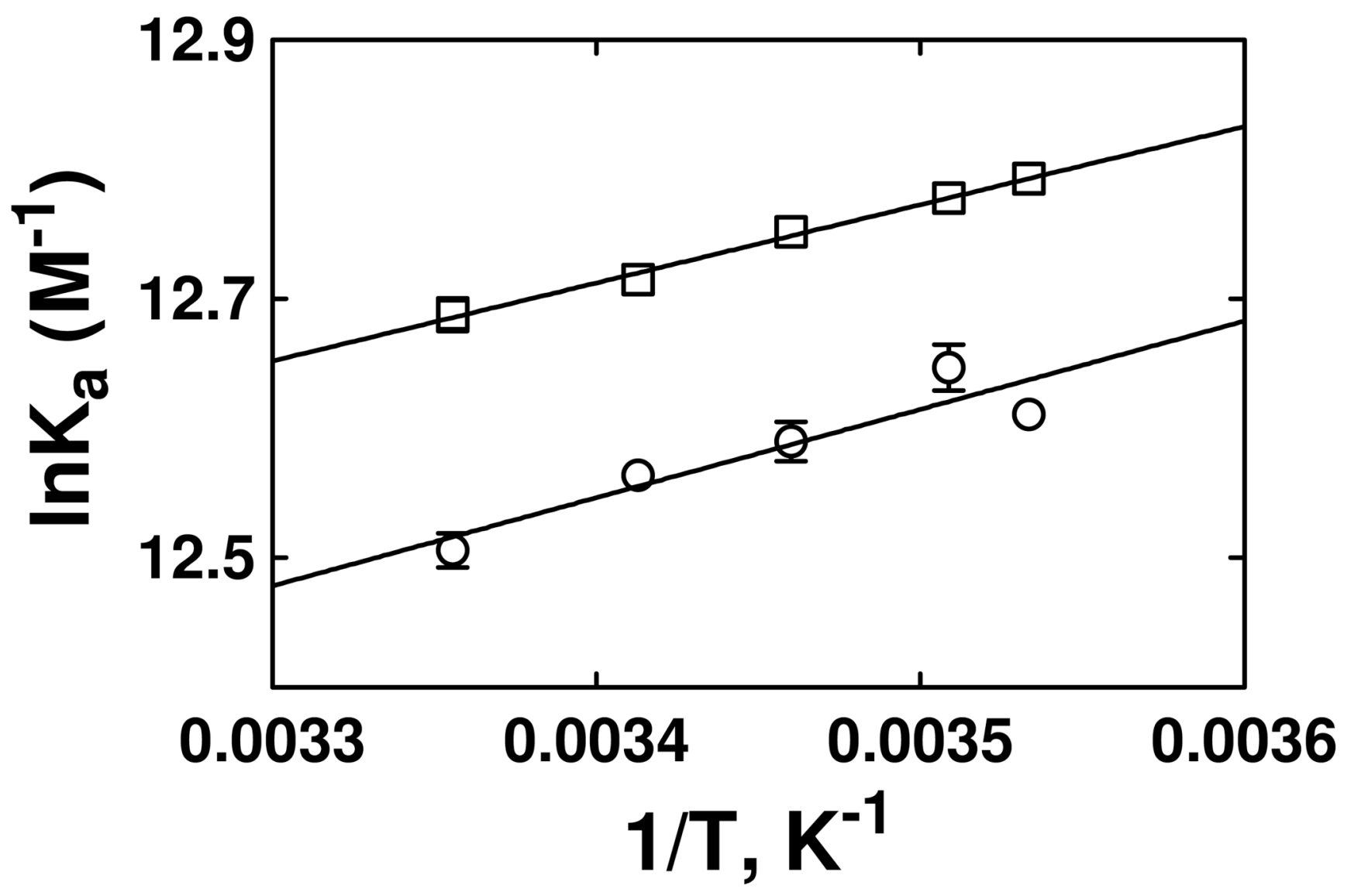

Fig. 5.

Van't Hoff plots of bupropion determined by elution from the CMAC-Torpedo AChR column at different temperatures (see Fig. 4B). Ammonium acetate buffer (10 mM, pH 7.4) and 15\% methanol were used as the mobile phase $(0.2 \mathrm{~mL} / \mathrm{min})$ to elute bupropion from the CMACTorpedo AChR column at different temperatures $\left(10-25^{\circ} \mathrm{C}\right)$. The column was pretreated with epibatidine ( $\square$ ) (the AChR is mainly in the desensitized state) or with $\alpha$-BTx ( $\square$ ) (the AChR is mainly in the resting state), respectively, before bupropion elution. The plots are the results from three experiments $(n=3)$, where the SD error bars are smaller than the symbol size. The observed $\mathrm{r}^{2}$ values are $0.995(\square)$ and $0.998(\circ)$, indicating that the plots are perfectly linear. The $\Delta H^{\circ}$ and $\Delta S^{\circ}$ values were determined using the slope $\left(\Delta H^{\circ}=-\right.$ Slope. $\left.\mathrm{R}\right)$ and $\mathrm{y}$-intercept $\left(\Delta S^{\circ}=\right.$ y-intercept $\left.\mathbf{R}\right)$ values from the plots, according to eq. 10 , where $\mathbf{R}$ is the gas constant (8.314 J K ${ }^{-1} \mathrm{~mol}^{-1}$ ). 
a
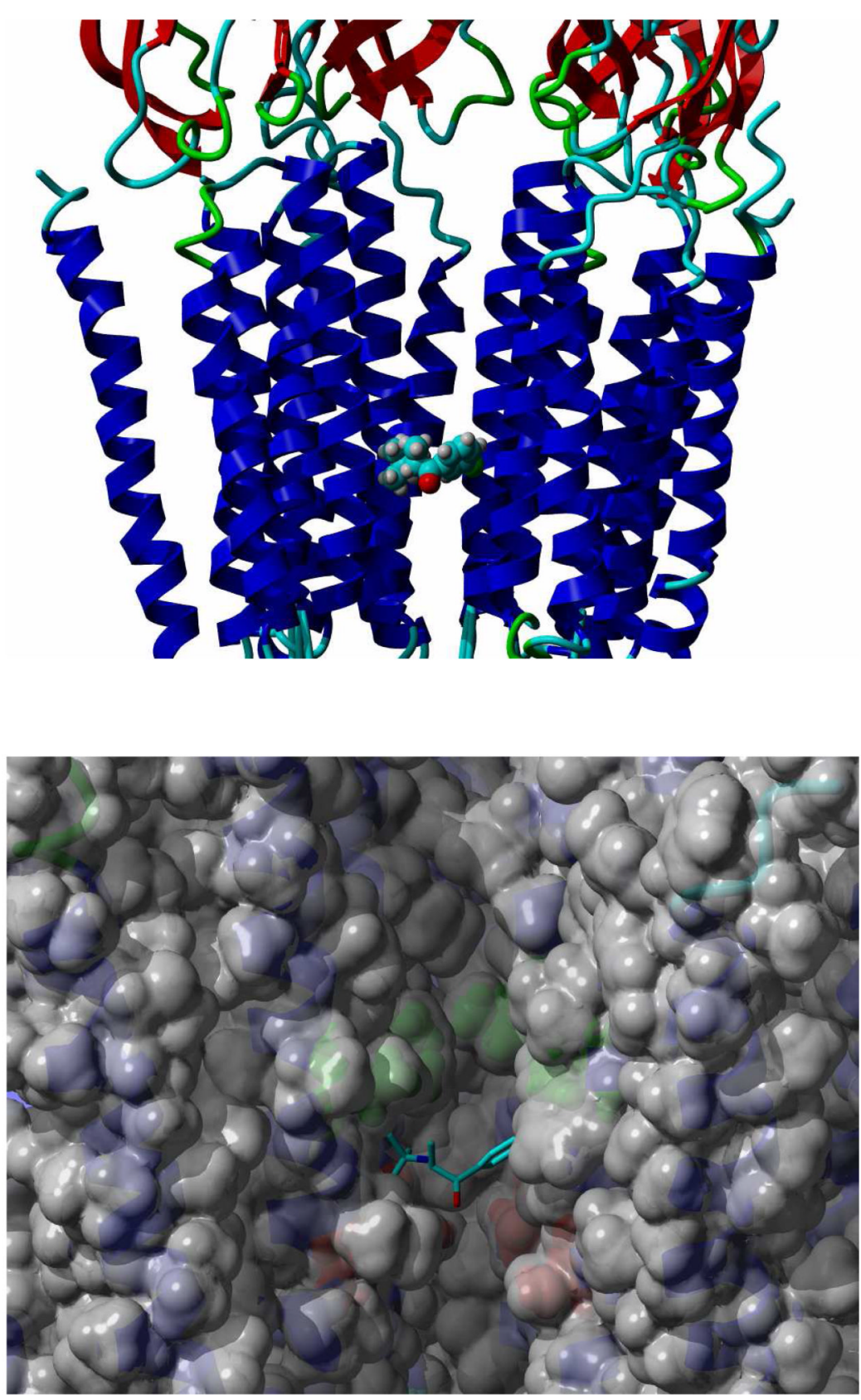


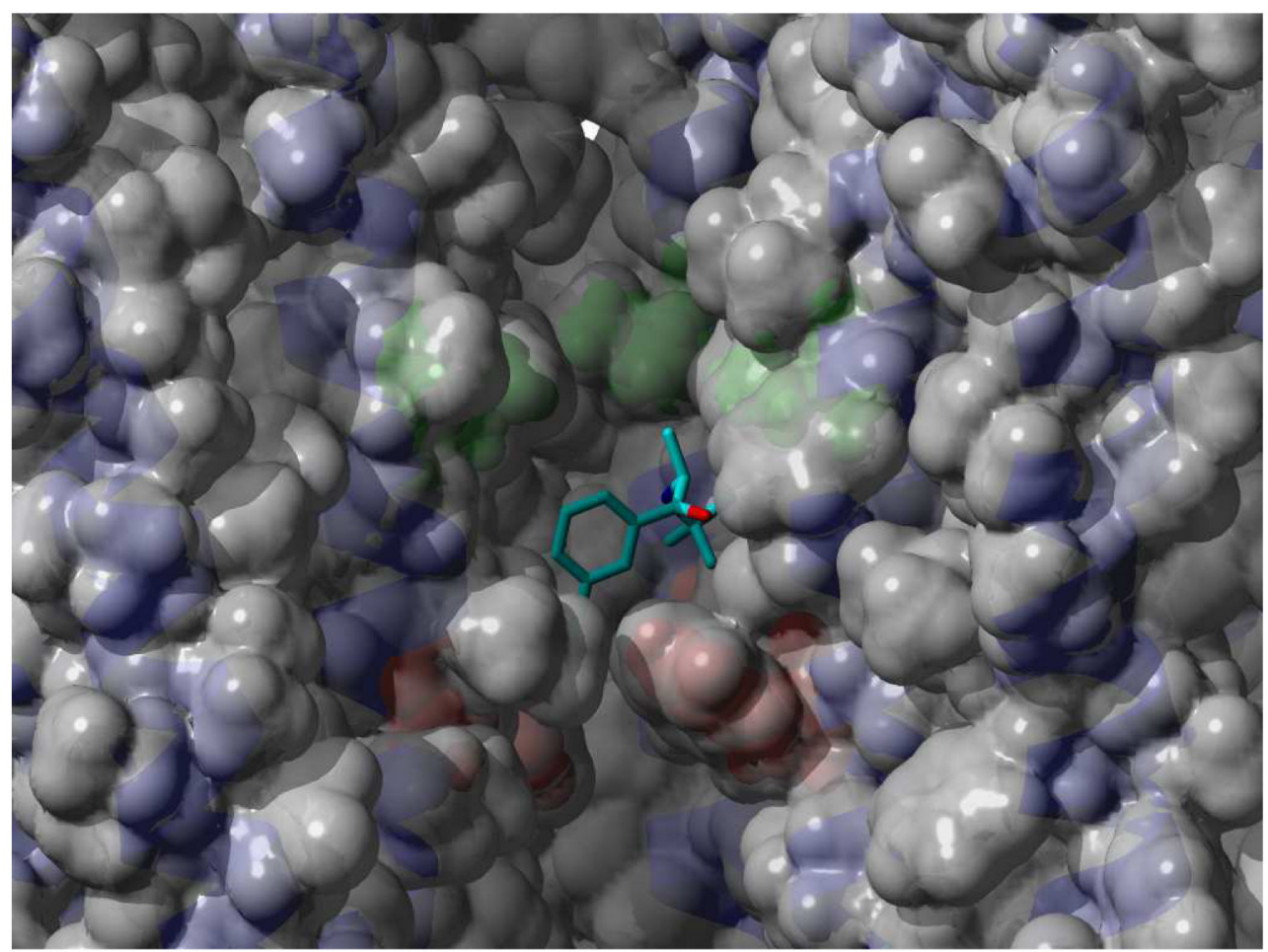

Fig. 6.

Complex formed between R-bupropion and the Torpedo AChR (a and b) and between Sbupropion and the mouse muscle AChR (c) ion channel obtained by molecular docking. (a) Side view of the lowest energy complex showing four Torpedo subunits rendered in secondary structure mode, whereas the ligand in the neutral form is rendered in element color coded ball mode. Side views of the Torpedo (b) and mouse muscle (c) AChR subunits rendered in semitransparent surface with visible secondary structure and explicit CPK atoms of residues forming the valine (position 13' in green) and serine (position 6' in red) rings. The ligand in the neutral form is rendered in stick mode with hydrogen atoms not shown explicitly. On both pictures the $\delta$ subunit was removed for clarity, and the order of remaining subunits is (from left to right) $\alpha 1, \gamma, \alpha 1$, and $\beta 1$. 


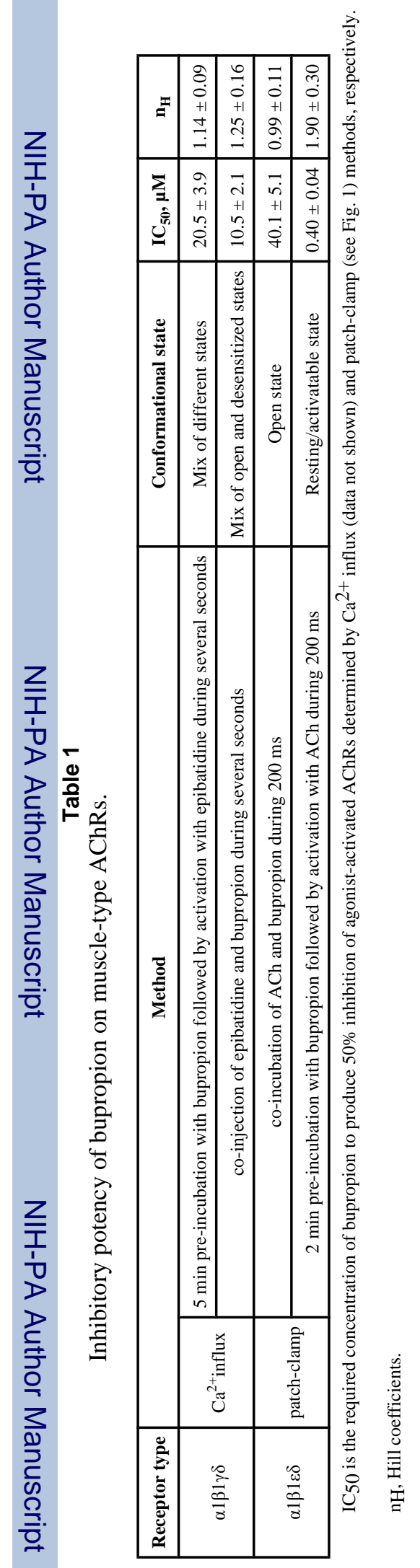

Biochemistry. Author manuscript; available in PMC 2010 June 2. 


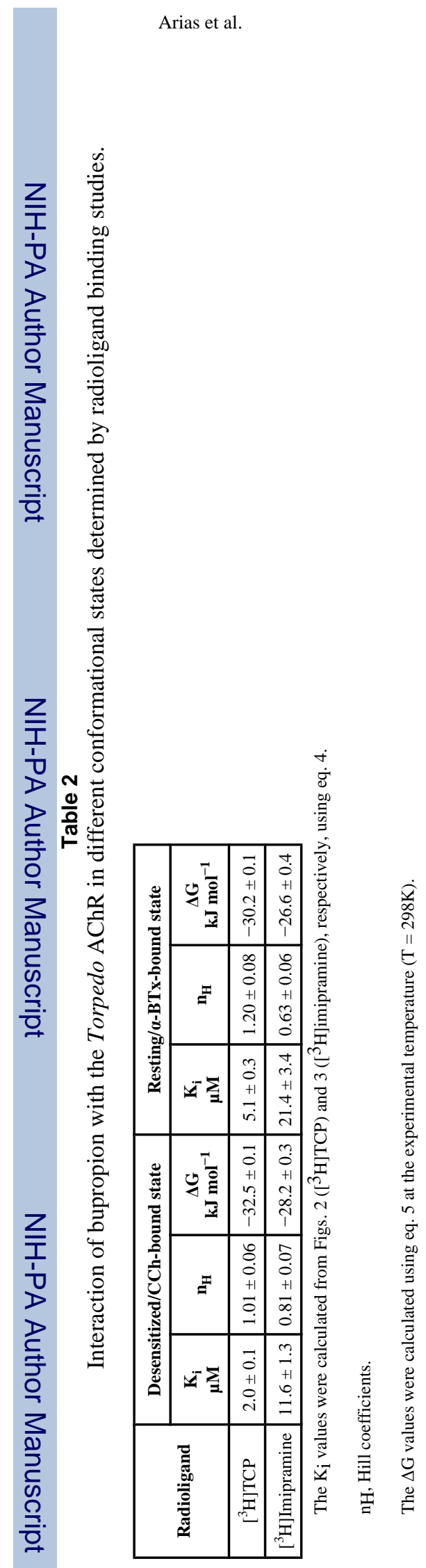

Biochemistry. Author manuscript; available in PMC 2010 June 2. 


\section{Table 3}

Kinetic and thermodynamic parameters of bupropion binding to Torpedo AChRs in different conformational states determined by non-linear chromatography studies.

\begin{tabular}{|c|c|c|}
\hline \multirow{2}{*}{ Parameter } & \multicolumn{2}{|c|}{ Condition } \\
\cline { 2 - 3 } & $\boldsymbol{\alpha}$-BTx treated column & Epibatidine treated column \\
\hline $\mathrm{k}_{\text {off }}\left(\mathrm{s}^{-1}\right)$ & $0.44 \pm 0.01$ & $0.50 \pm 0.02$ \\
\hline $\mathrm{k}_{\text {on }}\left(\mathrm{s}^{-1} \mu \mathrm{M}^{-1}\right)$ & $0.16 \pm 0.01$ & $0.15 \pm 0.02$ \\
\hline $\mathrm{K}_{\mathrm{a}}\left(\mu \mathrm{M}^{-1}\right)$ & $0.35 \pm 0.03$ & $0.29 \pm 0.04$ \\
\hline$\Delta \mathrm{G}^{20}\left(\mathrm{~kJ} \mathrm{~mol}^{-1}\right)$ & $-31.1 \pm 0.2$ & $-30.6 \pm 0.3$ \\
\hline
\end{tabular}

The CMAC-Torpedo AChR column was pretreated with either $\alpha$-BTx ${ }^{1}$ (the AChR is mainly in the resting state) or epibatidine ${ }^{2}$ (the $\mathrm{AChR}$ is mainly in the desensitized state).

The $\mathrm{k}_{\mathrm{Off}}$ and $\mathrm{K}_{\mathrm{a}}$ values were empirically determined from Fig. 4 and Fig. 5, respectively, according to eq. 6 and eq. 7 , respectively, whereas the $\mathrm{k}_{\mathrm{O}}$ values were calculated as $\mathrm{k}_{\mathrm{On}}=\mathrm{k}_{\mathrm{Off}}$. $\mathrm{K}_{\mathrm{a}}$.

The $\Delta \mathrm{G}$ values were calculated using eq. 5 at the experimental temperature $\mathrm{T}=293 \mathrm{~K}$. 


\section{Table 4}

Thermodynamic parameters of bupropion binding to the Torpedo AChR in different conformational states determined by non-linear chromatography studies and van't Hoff analysis.

\begin{tabular}{|c|c|c|}
\hline \multirow{2}{*}{ Thermodynamic parameters } & \multicolumn{2}{|c|}{ Condition } \\
\cline { 2 - 3 } & $\boldsymbol{\alpha}$-BTx treated column & Epibatidine treated column \\
\hline$\Delta \mathrm{H}^{\circ}\left(\mathrm{kJ} \mathrm{mol}^{-1}\right)$ & $-5.0 \pm 0.2$ & $-5.7 \pm 1.3$ \\
\hline$\Delta \mathrm{S}^{\circ}\left(\mathrm{J} \mathrm{mol}^{-1} \mathrm{~K}^{-1}\right)$ & $89 \pm 1$ & $85 \pm 5$ \\
\hline$\Delta \mathrm{G}^{20}\left(\mathrm{~kJ} \mathrm{~mol}^{-1}\right)$ & $-31.0 \pm 0.4$ & $-30.6 \pm 1.4$ \\
\hline
\end{tabular}

The CMAC-Torpedo AChR was pretreated with either $\alpha$-BTx ${ }^{1}$ (the AChR is mainly in the resting state) or epibatidine ${ }^{2}$ (the AChR is mainly in the desensitized state)

The thermodynamic parameters $\Delta \mathrm{H}^{\circ}$ and $\Delta \mathrm{S}^{\circ}$ were calculated from Fig. 5 according to eq. 8, and the $\Delta \mathrm{G}^{20}$ values were calculated using eq. 9. 


\section{Table 5}

MolDockScore values for the lowest energy of the AChR-bupropion complex obtained by molecular docking, and average binding energies of R- and S-bupropion (in the neutral form) interacting with Torpedo and mouse muscle AChR ion channels, respectively, calculated by molecular dynamics.

\begin{tabular}{|c|c|c|c|c|}
\hline \multirow{2}{*}{ Isomer } & \multicolumn{2}{|c|}{ Torpedo AChR } & \multicolumn{2}{c|}{ mouse muscle AChR } \\
\cline { 2 - 5 } & MolDockScore $\left(\mathbf{k J ~ m o l}^{-\mathbf{1}}\right)$ & Emulated binding energy $\left(\mathbf{k J ~ m o l}^{-\mathbf{1}}\right)$ & \left.${\text { MolDockScore }\left(\mathbf{k J ~ m o l}^{-\mathbf{1}}\right)}_{\mathrm{Emulated} \mathrm{binding} \mathrm{energy}(\mathbf{k J} \mathbf{~ m o l}}^{\mathbf{- 1}}\right)$ \\
\hline R-bupropion & -87.7 & $-104 \pm 10$ & -97.3 & $-118 \pm 12$ \\
\hline S-bupropion & -87.2 & $-115 \pm 9$ & -96.7 & $-113 \pm 13$ \\
\hline
\end{tabular}

The emulated binding energy was sampled every $5 \mathrm{ps}$ from a total of $1000 \mathrm{ps}$ of molecular dynamics simulation. Standard deviation values $( \pm$ SD) for emulated binding energy represent the fluctuations during molecular dynamics simulations. 